TRIBUNAL DE JUSTICIA DE LA UNIÓN EUROPEA 



\title{
LA TUTELA JUDICIAL DE LOS DERECHOS FUNDAMENTALES EN EL ÁMBITO DE APLICACIÓN NACIONAL DEL DERECHO DE LA UNIÓN EUROPEA. RECIENTES ACOTACIONES DEL TRIBUNAL DE JUSTICIA Y DEL TRIBUNAL CONSTITUCIONAL ESPAÑOL ${ }^{1}$
}

JUAN IGNACIO UGARTEMENDIA ECEIZABARRENA

Profesor de Derecho Constitucional y de la Unión Europea (Acreditado a Catedrático)

Universidad del País Vasco

\author{
SUMARIO \\ I. Introducción. \\ II. Cuestiones y problemas básicos acerca de la \\ tutela judicial de los Derechos Fundamen- \\ tales en el ámbito de aplicación interna del \\ Derecho de la Unión Europea. \\ III. Las recientes acotaciones del Tribunal de Jus- \\ ticia sobre la tutela de los DF en el ámbito de \\ aplicación nacional del Derecho de la Unión. \\ IV. Breves apuntes sobre las recientes acotaciones \\ del Tribunal Constitucional.
}

\section{INTRODUCCIÓN}

El objeto del presente trabajo es analizar ¿cómo se lleva a cabo la tutela judicial de los Derechos Fundamentales cuando se aplica Derecho de la Unión en el ámbito interno?

1 Una versión reducida de este texto fue presentada, el 10 de abril del presente, en el ciclo de conferencias dedicado a «La Unión Europea en el marco constitucional de los Estados Miembros» organizado por el profesor D. Ricardo Alonso García, en el marco del Seminario «García de Enterría» de la Universidad Complutense de Madrid. Aprovecho la ocasión para agradecer todos los comentarios que se me realizaron. La responsabilidad por los errores de los que pueda adolecer el texto es exclusivamente mía.

Este trabajo se ha realizado en el marco del PI del MICINN dedicado al estudio de «La eficacia de los Derechos Fundamentales de la Unión Europea: cuestiones avanzadas» (Ref. DER 2011-25795), así como del GIC IT675-13 y de la UFI 11/05 dedicados al estudio de la integración política y económica europea. 
o dicho de otra forma, ¿cuáles son los principales problemas con los que se topa el Juez nacional que aplica el Derecho de la Unión al desarrollar dicha función tuitiva? La forma de llevar a cabo el análisis consistirá en estudiar todo un cúmulo de recientes y decisivas resoluciones jurisdiccionales, dictadas tanto por parte del Tribunal de Justicia de la Unión Europea como, en lo que a España se refiere, por parte del Tribunal Constitucional, que analizan y acotan problemas y soluciones relativas a estas cuestiones, además de mostrar cuál es la evolución y el estado de la situación al respecto. Se trata, por una parte, de resoluciones que abordan cuestiones de fondo, como, por ejemplo: si es posible, y con qué límites, utilizar estándares nacionales de protección de los Derechos Fundamentales en situaciones conectadas con el Derecho de la Unión o con su aplicación, en lugar de utilizar el sistema de protección de los Derechos Fundamentales de la Unión Europea; o ¿Hasta qué punto posibilita la reforma del artículo 6 TUE realizada por el Tratado de Lisboa que el Juez nacional que actúa como Juez europeo pueda realizar un control de convencionalidad de una norma nacional que contradiga el CEDH? Y por otra, asimismo, existen resoluciones que atienden a cuestiones de dimensión más procesal como la consistente en dirimir el margen de autonomía que tiene el Juez nacional a la hora de plantear una petición prejudicial (se entiende a la hora de tutelar pretensiones o derechos reconocidos por normas de la Unión) en relación a las normas procesales nacionales o a la regulación sobre el control incidental de constitucionalidad activado por el juez nacional.

En cualquier caso, antes de dedicarnos al estudio de estas resoluciones en los siguientes apartados, y a efectos de contextualizar la incidencia de las mismas sobre la cuestión de la tutela judicial iusfundamental en el ámbito de aplicación nacional del Derecho de la Unión, dedicaremos un primer apartado a apuntar, siquiera de forma brevísima, los dos ejes de coordenadas sobre las que se asienta la cuestión y los problemas derivados. Por una parte, el tema de la identificación del ámbito de aplicación nacional de los Derechos Fundamentales de la Unión Europea (DFUE). Y por otra, el problema del «doble alma iusfundamental» (nacional y europea) que «padece» el Juez nacional que actúa como Juez la Unión.

\section{CUESTIONES Y PROBLEMAS BÁSICOS ACERCA DE LA TUTELA JUDICIAL DE LOS DERECHOS FUNDAMENTALES EN EL ÁMBITO DE APLICACIÓN INTERNA DEL DERECHO DE LA UNIÓN EUROPEA}

\section{II.1 La identificación del ámbito de aplicación nacional de los Derechos Fundamentales de la Unión Europea}

En cada uno de los Estados miembros de la Unión Europea existen y rigen tres sistemas de respeto y garantía de los derechos fundamentales. En primer lugar, el sistema establecido por la Constitución nacional, esto es, el sistema de los derechos fundamentales nacionales o, si se quiere, el de los estándares nacionales de protección de los Derechos Fundamentales. En segundo lugar, dentro de ese Estado actúa, igualmente, el sistema de derechos reconocido por Ordenamiento jurídico internacional, formado por todos los Tratados Internacionales sobre derechos humanos firmados y ratificados por ese Estado, pero donde destaca sobremanera, por motivos conocidos, el Convenio Europeo para la protección de 
los Derechos Humanos y de las Libertades Fundamentales o $\mathrm{CEDH}^{2}$. Unido a ambos, la forja del Derecho comunitario y de la Unión Europea ${ }^{3}$, ha terminado por generar un tercer sistema de reconocimiento y garantía de los Derechos Fundamentales, un sistema europeocomunitario que no sólo actúa vis-à-vis la actividad de las instituciones y órganos de la Unión, sino que opera también ante la actividad de los Estados miembros cuando estos actúan en el radio de acción del Derecho de la Unión. Véase el Informe de la Comisión al Parlamento Europeo, al Consejo, al Comité Económico y Social Europeo y al Comité de las Regiones: «Informe de 2012 sobre la aplicación de la carta de los Derechos Fundamentales de la UE», Bruselas, 8 de mayo de 2013, COM (2013) 271 final, esp. ap. 3. Veámoslo.

Como es sabido, la Unión Europea no ha dispuesto de una Carta propia de Derechos Fundamentales hasta diciembre del año 2000, momento en que se proclama la llamada Carta de Derechos Fundamentales de la Unión Europea (Carta de DFUE) en la ciudad francesa de Niza, aunque sólo a titulo declarativo, sin eficacia jurídica normativa o vinculante. Esta eficacia u obligatoriedad jurídica sólo se alcanzo a primeros de diciembre del año 2009, cuando entra en vigor el Tratado de Lisboa (aprobado en 2007), un Tratado de reforma de los Tratados constitutivos que estableció que aquella Carta de DFUE tiene el «mismo valor jurídico que los Tratados» (nuevo artículo 6.1 del TUE). No obstante, a pesar del silencio inicial de los Tratados, y del carácter reciente de la vinculatoriedad jurídica de la Carta, la Unión ya venía reconociendo (al comienzo desde las Comunidades Europeas) un sistema de reconocimiento y tutela de los Derechos Fundamentales establecido a partir de la jurisprudencia del Tribunal de Justicia de las Comunidades Europea (hoy Tribunal de Justicia de la Unión Europea). Desde hace ya más de cuarenta años, este Tribunal viene asumiendo la idea de que los Derechos Fundamentales son algo cuya protección no puede omitir u obviar el Derecho comunitario, debiendo ser tratados como «principios generales del Derecho comunitario» deducibles por el TJCE de las «tradiciones constitucionales comunes» de los Estados miembros así como de los Tratados Internacionales para la protección de los derechos humanos en los que los Estados miembros han colaborado o de los que sean signatarios.

Pero, como ya se ha avanzado, el hecho es que, aunque inicialmente los DFUE sólo tenían una capacidad jurídicamente vinculante ante la actuación de las instituciones y órganos comunitarios (ámbito o radio de acción europeo) ${ }^{4}$, más tarde el TJUE identificó,

2 No sólo porque cada Estado miembro de la Unión Europea es parte del Consejo de Europa y está sometido al respeto del Convenio y a la jurisdicción del Tribunal de Derechos Humanos de Estrasburgo, sino que también por el peso que dicho Convenio ha tenido y va a seguir teniendo dentro del ámbito de la Unión Europea (como puede descubrirse atendiendo el contenido de los apartados 2 y 3 del artículo 6 del TUE o de los artículos 52.3 y 53 de la Carta de Derechos Fundamentales de la Unión).

3 En principio, y salvo especificación en contra, usaré de forma indistinta las expresiones Derecho u ordenamiento «comunitario» y Derecho u ordenamiento «de la Unión Europea».

4 Para un análisis reciente acerca de la vinculación de los DFUE sobre la actuación administrativa europea: Irurzun Montoro, F., «Régimen Jurídico de la Administración Europea y Derechos Fundamentales», Soriano, J.E. (Dir.), Procedimiento Administrativo Europeo, Civitas/Thomson Reuters, 2012, pp. 287 y ss. Acerca de la tutela judicial efectiva de los Derechos Fundamentales en el ámbito de la imposición de medidas de carácter sancionador por la UE: JANer TorRens, J.D., «La tutela de los Derechos Fundamentales en la adopción de medidas sancionadoras por la Unión Europea», Revista de Derecho Comunitario Europeo, 43, 2012, pp. 773 y ss.; vid. también, al respecto, ECKES, C., EU Counter-Terrorist policies and fundamental rights: the case of individual sanctions, OUP, Oxford, 2009. 
asimismo, un ámbito de actuación interna o nacional de esos DFUE. El hito jurisprudencial del Tribunal de Luxemburgo que inaugura esta extensión o expansión de la eficacia vinculante de los DFUE sobre la actuación estatal es la Sentencia al asunto Wachauf ${ }^{5}$, un decisión que comienza a establecer de forma clara que los Estados miembros tienen también la obligación de respetar dichos derechos, si bien (solo) «cuando actúan en el ámbito de aplicación del Derecho comunitario», esto es, cuando actúan aplicando normativa comunitaria. Se trata del comienzo de toda una línea jurisprudencial, sobre la que luego volveremos, que hace surgir en el ámbito estatal interno un nuevo sistema iusfundamental — o sistema relativo a Derechos Fundamentales_ que vincula también la actividad del poder público estatal, eso sí, siempre que éste actúe en aplicación del Derecho de la Unión. Más tarde, la propia Carta vendrá a formalizar esa operatividad nacional de los DFUE al establecer, en su artículo 51.1, que los Derechos reconocidos en la misma vinculan tanto a la Unión como a los Estados «cuando aplican el Derecho de la Unión».

Este reconocimiento de la operatividad nacional de los DFUE se topará de inmediato con el problema de identificar ¿cómo se conforma de manera concreta ese «ámbito de aplicación nacional» del Derecho de la Unión y, por tanto, de respeto a los DFUE? ¿Qué actuación interna entra y cuál no entra en el mismo? Un problema de delimitación precisa de la extensión o amplitud de la esfera de actuación nacional sometida a esos derechos sobre el que el Tribunal ha venido estableciendo pautas desde hace tiempo.

En este sentido, hay que decir que la jurisprudencia del Tribunal de Justicia anterior a la entrada en vigor de la reforma Lisboa (2009), y por tanto a la eficacia jurídica vinculante de la Carta en el ámbito interno (arts. 6.1 TUE y 51.1 de la Carta), asumía una concepción amplia del concepto de «ámbito de aplicación» del Derecho de la Unión identificándola prácticamente con la idea de radio de acción del Derecho de la Unión. Esto es, los Estados miembros estarían obligados a respetar los DFUE (entendidos como principios generales del Derecho) no sólo cuando «ejecutan» Derecho de la Unión —en el sentido estricto de la expresión- (situación en la que el Estado actúa como mero «agente» de la Unión) ${ }^{6}$, sino que también cuando pretenden «derogarlo» ${ }^{7}$ «excepcionarlo» ${ }^{8}$, en el caso de que así esté permitido por el Derecho de la Unión, y en general, siempre que exista un elemento de conexión (suficiente) entre la actividad nacional y el Derecho de la Unión (sin perder de vista, además, que el Tribunal de Justicia tiene tendencia a interpretar en sentido generoso la existencia de dicha conexión $\left.{ }^{9}\right)^{10}$. La entrada en vigor de la Carta, y con ella de su artículo 51.1, en el que se recuerda que las disposiciones de ésta deberán ser respetadas por

5 De 13 de julio de 1989 (C-5/88) [«... las exigencias derivadas de la protección de los derechos fundamentales en el ordenamiento jurídico comunitario (...) vinculan, asimismo, a los Estados miembros cuando aplican la normativa comunitaria, de lo que resulta que estos últimos están obligados, en lo posible, a aplicar dicha normativa de modo que no menoscaben tales exigencias» (apartado 19)].

6 Sentencia TJ, de 13 de julio de 1989, as. Wachauf, C-5/88.

7 El supuesto clásico es el de la ya citada STJ de 18 de junio de 1991, as. ERT, C-260/89.

8 Por ejemplo: SSTJ: de 26 de mayo de 1997 as. Familiapress, C-368/95; de 12 de junio de 2003, as. Schmidberger, C-112/00; de 14 de octubre de 2004, as. Omega, C-36/02.

9 Por ejemplo: STJ de 10 de julio de 2003, s. Booker Aquaculture, C-20/00 y C-64/00.

10 Cfr., ex plurimis, Alonso García, R., Sistema jurídico de la Unión Europea, op. cit., p. 376; MANGaS Martín, A., «Comentario al artículo 51», en la obra dirigida por dicha profesora: Carta de Derechos Fundamentales de la Unión Europea... op.cit., pp. 816 ss.; Groussot, X.; Pech, L. y Petersson, G.T., The scope of application EU Fundamental Rights on Member States'action: In search of certainty in EU adjudication, E. Stein 
los Estados miembros «únicamente cuando apliquen el Derecho de la Unión», ha traído a colación la cuestión de si el ámbito de aplicación delimitado por ésta es más restringido que el utilizado previamente por la jurisprudencia del Tribunal de Justicia que tutela los DFUE en cuanto principios generales del Derecho comunitario (y/o de la Unión ${ }^{11}$ ). No obstante, la jurisprudencia del Tribunal de Justicia ${ }^{12}$, así como gran parte de la doctrina ${ }^{13}$, continúan asumiendo una concepción amplia o extensiva del ámbito de aplicación de los DFUE, identificable con la que se reconoce a los DFUE en cuanto principios generales del Derecho de la Unión. Todo lo cual, no quita, ciertamente, que sigan existiendo problemas concretos, dependiendo de los diferentes supuestos, a la hora de calibrar la existencia de una conexión suficiente entre la actividad nacional y el Derecho de la Unión.

\section{II.2 La tutela judicial efectiva de los DFUE en el ámbito nacional y la problemática derivada del «doble alma iusfundamental» del Juez nacional como Juez comunitario}

El sistema judicial de la Unión Europea no reside solo en el Tribunal de Justicia de la Unión Europea o TJUE [integrado por el Tribunal de Justicia o TJ, el Tribunal General o TG y los «Tribunales especializados» $]^{14}$, sino en todo un conjunto jurisdiccional que engloba

Working Paper (http://www.ericsteinpapers.eu), 1/2011, pp. 4 y ss.; Rosas, A. y Armati, L., EU Constitutional Law. An Introduction, Hart Publishing, Oxford and Portland, 2012, pp. 164 y ss.

11 Recuérdese que, si el art. 6.1 TUE establece la plena vigencia jurídica de la Carta con el mismo valor que los Tratados, el artículo 6.3 del Tratado reconoce, formalizando la jurisprudencia iusfundamental previa, que: «Los derechos fundamentales que garantiza el Convenio Europeo para la Protección de los Derechos Humanos y de las Libertades Fundamentales y los que son fruto de las tradiciones constitucionales comunes a los Estados miembros formarán parte del Derecho de la Unión como principios generales».

12 Por ejemplo: STJ de 19 de enero de 2010, as. Kücükdeveci, C-555/07, apartados 22 y ss.; STJ de 23 de noviembre de 2010, as. Tsakouridis, C-145/09, apartados 50-52. O en la STJ de 26 de febrero de 2013, as. Akerberg, C-617/10, apartados 17 y ss., sobre la que volveremos más tarde. Véanse igualmente, en este sentido, por ejemplo, las Conclusiones de la Abogada General E. Sharpston, de 30 de septiembre de 2010, as. Ruiz Zambrano, C-34/09, apartados 156 ss.; o del Abogado General Yves Bot, de 5 de abril de 2011, en el as. Ivana Scattolon, C-108/10, apartados 110 y ss. No parece, además, como recuerda este último Abogado General (ibid.) en los apartados 118 y 119 de sus Conclusiones, que la fórmula elegida por los redactores de la Carta haya querido restringir el ámbito de aplicación de la misma en relación con la jurisprudencialmente estipulada por el TJ para el ámbito de aplicación de los principios generales del Derecho de la Unión. Así lo acreditarían las explicaciones relativas al artículo 51.1 de la Carta que, conforme al último pár. del art. 6.1 TUE y al 52.7 de la Carta, deben tenerse en cuenta para su interpretación.

13 Entre otros: Lenaerts, K.; Gutiérrez-Fons, J.A., «The constitutional allocation of powers and general principles of EU law», CMLR, 47, 2010, pp. 1629 y ss., espec. pp. 1657 y ss.; EGGER, A., «EUFundamental Rights in the National Legal Order: The Obligations of Member States Revisited», Yearbook of European Law, 25, 2006, pp. 515 y ss.; Groussot, X.; Pech, L.; Petersson, G.T., The scope... op. cit., pp. 16 у ss.; Кокотт, J.; Sовотта, Сн., The Character of Fundamental Rights of the European Union after Lisbon, EU Working Papers, AEL 6/2010; Von Bogdandy, A. et alii: "Cómo proteger los derechos fundamentales europeos frente a los Estados miembros», en Von Bogdandy, A.; Ugartemendia, J.A.; Saiz Arnaiz, A.; Morales, M. (Coords.), La tutela jurisdiccional de los derechos. Del constitucinalismo histórico al constitucionalismo de la integración, IVAP/MPI, Oñati, 2012, espec. pp. 145 y ss. Para la visión de la Comisión sobre la Aplicación de la Carta en los Estados Miembros, véase el ya mencioado «Informe (de la Comisión) de 2012 sobre la aplicación de la Carta...», Bruselas, 8 de mayo de 2013, espec. apartado 3.

14 Según establece el primer párrafo del artículo 19.1 TCE: «El Tribunal de Justicia de la Unión Europea comprenderá el Tribunal de Justicia, el Tribunal General y los tribunales especializados. Garantizará el 
también además a todos los órganos jurisdiccionales de los Estados miembros. Los órganos que integran el TJUE son los únicos órganos jurisdiccionales propiamente de la Unión Europea, pero no son los únicos jueces encargados de aplicar el Derecho de la Unión, pues también corresponde esa función, y de una forma «crucial», a los órganos jurisdiccionales nacionales ${ }^{15}$ (y ello a pesar de que la reforma de Lisboa siga sin solucionar la ausencia de referencia expresa al «Juez nacional» como parte esencial de la arquitectura judicial europea o que tampoco haya dado debido reflejo a todo el arsenal de poderes-deberes que el Tribunal de Justicia ha ido poniendo en las manos del mismo — por ejemplo, obligación de inaplicar ley nacional contraria al Derecho comunitario-, y el reconocimiento de ese fundamental papel se haya quedado plasmado sólo de forma implícita en el segundo párrafo del artículo $19.1 \mathrm{TUE}^{16}$ ). Aquellos poseen la competencia sobre la interpretación «definitiva» del Derecho de la Unión y sobre la apreciación de la validez de los actos de las instituciones europeas, pero, sin embargo, la competencia de «aplicación» jurisdiccional de aquel Derecho está repartida entre los órganos jurisdiccionales nacionales y los Tribunales de la Unión: (a) mientras estos Tribunales actúan a través de unas concretas «competencias de atribución» (esto es, resolviendo las cuestiones prejudiciales, el recurso de anulación, el recurso por incumplimiento, o el de responsabilidad extracontractual de las Comunidades, etc.); (b) el Juez nacional tiene la competencia para solucionar, en materia de aplicación del Derecho de la Unión, el conjunto del contencioso entre particulares, entre los particulares y los Estados miembros, y entre particulares y la Unión (en materia contractual). Y en este sentido, se afirma que los órganos jurisdiccionales nacionales son los jueces de «Derecho común» para la aplicación del Derecho comunitario ${ }^{17}$. De manera que es el Juez nacional el Juez garante - cotidiano- de los derechos que el ordenamiento de la Unión atribuye y reconoce a los particulares, y entre ellos, también el garante de los DFUE o Derechos Fundamentales reconocidos por el ordenamiento de la Unión (sean los de la Carta o a título de principios generales de la Unión reconocidos por el TJ), si bien esa función tuitiva debe ser ejercida a través de una relación esencial de cooperación con el Tribunal de Justicia. Una cooperación que, como es sabido, se articula, principalmente, mediante la cuestión prejudicial, de interpretación o, en su caso, de validez, establecida en el art. 267 TFUE.

Ahora bien, el Juez nacional que aplica Derecho de la Unión no es sólo el Juez encargado - por el Derecho de la Unión- de la tutela de los DFUE en el caso concreto, es también, aunque huelga decirlo, el Juez constitucionalmente constreñido a la tutela

respeto del Derecho en la interpretación y aplicación de los Tratados». Sobre las modificaciones generadas por el Tratado de Lisboa en la arquitectura judicial de la Unión, véase: AlONO GARCía, R., «Lisboa y el Tribunal de Justicia de la Unión Europea», Papeles de Derecho Europeo e Integración Regional, WP IDEIR n. ${ }^{\circ} 1$, 2010; el mismo, en su Sistema jurídico de la Unión Europea, op. cit., pp. 181 y ss.

15 El Tribunal de Justicia de Luxemburgo tiene establecida desde antiguo la obligación de garantizar, a través de los órganos jurisdiccionales nacionales, la protección jurídica de los derechos que el ordenamiento comunitario otorga a los particulares (Sentencia Rewe, de 16 de diciembre de 1976, C-33/76), obligación cuyo correlato es el reconocimiento comunitario del «derecho al juez» o a la tutela judicial efectiva en el ámbito comunitario (Johnston, de 15 de mayo de 1986, C-222/84; o Heylens, de 15 de octubre de 1987, C-222/86), hoy ya vinculantemente reconocido también en el artículo 47 de la Carta de DFUE.

16 Cuando señala que «los Estados miembros establecerán las vías de recurso necesarias para garantizar la tutela judicial efectiva en los ámbitos cubiertos por el Derecho de la Unión».

17 Véase García de EnTERría, E., «Perspectivas de las justicias administrativas nacionales en el ámbito de la Unión Europea», REDA, 103, 1999, p. 403. 
de los Derechos reconocidos por el ordenamiento nacional, de forma particular de los Derechos Fundamentales reconocidos por la Constitución (arts. 9.1, 53 y 117 CE ó 7.2 de la LOPJ). Y es aquí, donde surge una especie de «doble alma iusfundamental» del Juez nacional, un alma jurisdiccional que se debe a los Derechos Fundamentales de la Constitución nacional pero también a los DFUE (o si se prefiere, a los estándares de protección de los Derechos Fundamentales de fundamento nacional y a los de base eurocomunitaria), como una concreción de su doble condición de «Juez nacional» y de «Juez nacional que actúa como Juez comunitario».

En principio y en teoría, cabría pensar que las ya clásicas reglas y principios de articulación entre el Derecho de la Unión y el Derecho nacional (efecto directo, primacía, interpretación conforme, autonomía institucional, etc.), unidas a la arriba mencionada doctrina jurisprudencial Wachauf y a los dictados del artículo 51.1 de la Carta, dejan bastante claro que ese Juez nacional con doble alma iusfundamental debe hacer «primar» el sistema europeo sobre el sistema nacional siempre, eso sí, que esté aplicando Derecho de la Unión. Esto es, parece «evidente» que debe atenerse, en resumidas cuentas, a utilizar como parámetro de enjuiciamiento a los DFUE antes que los derechos reconocidos en la Constitución nacional. Pese a todo, el tener que dar por buenos éste y aquellos otros principios mencionados arriba no ha eliminado todos los problemas y dudas que derivan de esa duplicidad iusfundamental que sostiene el alma jurisdiccional del Juez nacional. Es verdad que el hecho de que en la mayoría de los casos coincidan los estándares nacionales y comunitarios de tutela de los Derechos Fundamentales lleva a pensar bien que no hay por qué dejar de aplicar el sistema iusfundamental nacional o bien a dejarse guiar por una especie de inercia tuitiva a utilizar este sistema, descuidando el hecho de que los problemas pueden surgir y necesitan soluciones meditadas.

En efecto, no obstante lo dicho, las dudas y los problemas existen y, de vez en cuando, asoman con fuerza, especialmente sobre las espaldas de ese Juez nacional que debe actuar como Juez comunitario e, incluso, como veremos, sobre el Tribunal Constitucional que está controlando si el Juez nacional que aplica Derecho de la Unión respeta o no la tutela judicial efectiva (art. 24 CE)]: ¿Debe ese Juez nacional priorizar el sistema iusfundamental de la Unión Europea en todo caso? ¿Incluso cuando el Estado ha tenido mucho margen a la hora de decidir cómo aplicar normativamente el Derecho de la Unión (y no se trata simplemente de una ejecución estatal en sentido estricto de una norma comunitaria)? ¿Es posible considerar que se atiende a la obligación de tutelar los DFUE cuando esa tutela se vehicula tutelando los derechos constitucionales a través de cláusulas de apertura constitucional a los DFUE como la establecida en el artículo 10.2 CE? ¿Es posible entender que el artículo 53 de la Carta de DFUE establece un estándar mínimo de protección europeo fijado, en cada caso, por la Constitución nacional ${ }^{18}$ ? ¿Hasta qué punto cabe pensar que el Juez nacional que aplica Derecho de la Unión

18 Artículo 53: «Nivel de protección: Ninguna de las disposiciones de la presente Carta podrá interpretarse como limitativa o lesiva de los derechos humanos y libertades fundamentales reconocidos, en su respectivo ámbito de aplicación, por el Derecho de la Unión, el Derecho internacional y los convenios internacionales de los que son parte la Unión o todos los Estados miembros, y en particular el Convenio Europeo para la Protección de los Derechos Humanos y de las Libertades Fundamentales, así como por las constituciones de los Estados miembros.» 
puede inaplicar una norma nacional que contradiga el CEDH a la luz de las últimas modificaciones del Tratado de Lisboa (apartados 2 y 3 del artículo 6 TUE y 52.3 de la Carta)? ¿Hasta qué punto o con qué límites puede combinarse —en nuestro caso, a la hora de tutelar los DF en el ámbito de aplicación nacional del Derecho de la Unión- la facultad o, en su caso, la obligación del Juez nacional de plantear la cuestión prejudicial (planteada enel contexto de la tutela de los derechos reconocidos por normas de la Unión) con las reglas procesales que le marca el ordenamiento interno?, etc.

En las próximas páginas trataremos de analizar una serie de resoluciones del Tribunal de Justicia, y también del Tribunal Constitucional, recaídas recientemente, que vienen a responder a una buena parte de estos problemas, estableciendo algunas respuestas o, en su caso, ciertas pautas de solución a los mismos.

\section{LAS RECIENTES ACOTACIONES DEL TRIBUNAL DE JUSTICIA SOBRE LA TUTELA DE LOS DF EN EL ÁMBITO DE APLICACIÓN NACIONAL DEL DERECHO DE LA UNIÓN}

En los últimos años, el Tribunal de Justicia viene adoptando, en efecto, una serie de sentencias, algunas muy recientes, que vienen, precisamente, a señalar una serie de acotaciones a los problemas generales que se acaban de mencionar, problemas algunos de dimensión más bien sustantiva o de fondo, y otros con un cariz más de tipo procesal. Por una parte, y por lo que se refiere a los problemas de carácter sustantivo, cabe destacar, en primer lugar, las Sentencias Melloni y Akerberg, recaídas ambas el mismo 26 de febrero de 2013, las cuales vienen a aclarar hasta qué punto debe utilizarse siempre el parámetro iusfundamental de los DFUE a la hora tutelar los derechos fundamentales frente a la actuación estatal que aplica Derecho de la Unión. A modo de segunda acotación sustantiva, merece la pena resaltar, asimismo, la existencia de resoluciones del TJ (Kamberaj y Akerberg) que afectan al hecho de cómo queda, tras la reforma de Lisboa, la cuestión de un control de convencionalidad (CEDH) en manos del Juez nacional que actúa como Juez de la Unión ante la norma nacional. Por otra parte, procede resaltar, igualmente, una serie de decisiones del Tribunal de Luxemburgo recaídas en los últimos años que, capitaneadas por la STJ Melki o la reciente Sentencia Križan, vienen también a acotar y resolver algunos problemas atinentes a las posibilidades y límites existentes a la hora de combinar la cuestión prejudicial con las reglas procesales internas. Veámoslo de forma más detenida.

\section{III.1 Acotaciones sustantivas (I): La «regla de las situaciones iusfundamentales»}

\section{III.1.1 El problema-dilema del parámetro iusfundamental: el asunto Melloni}

La cuestión sobre qué parámetro iusfundamental o qué estándar nacional de protección de los derechos fundamentales (nacional o de la Unión Europea) debe utilizar el Juez nacional que aplica Derecho de la Unión, y con qué posibilidades y límites, es una cuestión que el Tribunal acaba de afrontar con claridad a través de dos recientes Sen- 
tencias (a estos efectos complementarias): la Sentencia Melloni y la Sentencia Akerberg, ambas del 26 de febrero de 2013.

\section{(A) El asunto Melloni: la STJ Melloni y su antecedente el ATC 86/20 i i, CON EL QUE EL TC PLANTEA SU PRIMERA CUESTIÓN PREJUDICIAL}

El 26 de febrero de 2013 el Tribunal de Justicia (TJ) dictó su Sentencia en el asunto Melloni (C-399/11), dando respuesta a la cuestión prejudicial que el Tribunal Constitucional de España (TC) le había formulado en su Auto 86/2011, de 9 de junio. Este asunto versa sobre la aplicación judicial de una Orden Europea de Detención y Entrega (OEDE o euroorden), en concreto de entrega para el cumplimiento de condena. La figura de la euroorden fue creada por la Decisión Marco 2002/584/JAI del Consejo, de 13 de junio de 2002, relativa a la orden de detención europea y a los procedimientos de entrega entre Estados miembros ${ }^{19}$, modificada en 2009 por la Decisión Marco 2009/299/JAI del Consejo, de 26 de febrero, destinada a reforzar los derechos procesales de las personas y a propiciar la aplicación del principio de reconocimiento mutuo de las resoluciones dictadas a raíz de juicios celebrados sin comparecencia del imputado ${ }^{20}$. La Decisión Marco (DM) que regula la euroorden no es directamente aplicable por las autoridades judiciales de los Estados miembros. Según se establece en su art. 34, los Estados miembros habrán de tomar medidas legislativas para dar cumplimiento a lo dispuesto en la misma. España fue el primer Estado en trasponer la Decisión Marco. Lo hizo mediante la aprobación de la Ley 3/2003, de 14 de marzo, sobre la OEDE (BOE de 17 de marzo) y la LO 2/2003, de 14 de marzo, complementaria a la Ley sobre OEDE (BOE de 17 de marzo). En España no se ha cuestionado la constitucionalidad en abstracto de la Ley $3 / 2003^{21}$; sí ha habido, en cambio, demandas de amparo en las que el recurrente ha alegado la violación por las correspondientes resoluciones de la Audiencia Nacional de diversos derechos fundamentales reconocidos en la Constitución Española, por lo general los relacionados en el art. 24. $\mathrm{CE}^{22}$. De este modo el Tribunal

19 «DO»L 190, de 17 de julio de 2002, p. 1.

20 «DO» L 81, de 27 de marzo de 2009, p. 24. La OEDE o euroorden consiste en una resolución judicial dictada en un Estado miembro de la Unión Europea con vistas a la detención y entrega por otro Estado miembro de una persona a la que se reclama para: a) el ejercicio de acciones penales (entrega para el enjuiciamiento), b) la ejecución de una pena o de una medida de seguridad privativa de libertad (entrega para el cumplimiento de condena), que es el caso del asunto Melloni. La euroorden sustituye en los Estados miembros de la Unión Europea al tradicional sistema de extradición, respecto del que introduce cambios significativos. La OEDE es, por consiguiente, un mecanismo de cooperación entre las autoridades judiciales de los Estados miembros de la Unión Europea basado en «el principio de reconocimiento mutuo, que permite la ejecución prácticamente automática de las resoluciones dictadas por las autoridades judiciales de los demás Estados».

21 El proceso de transposición de la Decisión Marco y el desarrollo de la OEDE en los diferentes Estados no ha estado exentos de problemas y ha requerido la intervención tanto de varios Tribunales constitucionales (Polonia, Alemania, República Checa, Chipre, y muy recientemente, como apuntaremos luego, Francia) que han realizado un análisis de la constitucionalidad de las respectivas leyes de transposición de la Decisión Marco, como la del TJ de la Unión.

22 Entre otras, SSTC 83/2006, de 13 de marzo, y 293/2006, de 10 de octubre Ver, también, SSTC 211/2005, de 18 de julio 292/2005, de 10 de noviembre 328/2005, de 12 de diciembre 339/2005, de 20 de diciembre 30/2006, de 30 de enero 177/2006, de 5 de junio, STC 199/2009; y AATC 37/2007, de 12 de febrero 95/2007, de 7 de mayo. Sobre el tema, in extenso: Ripol Carulla, S., «La jurisprudencia del Tribunal 
Constitucional ha actuado como tribunal de defensa de los derechos fundamentales y dado respuesta a las quejas concretas que, al hilo de la aplicación de la Ley 3/2003, le han sido sometidas. Y este es también, el caso del ATC 86/2011.

La Sentencia Melloni, como decimos, es la respuesta a las cuestiones prejudiciales planteadas, por vez primera, por el TC en el ATC 86/2011 23 , Auto que surge en el contexto de un recurso de amparo. El recurrente, de nacionalidad italiana, había sido juzgado en rebeldía en Italia. La Sección Primera de la Sala de lo Penal de la Audiencia Nacional, mediante Auto de 12 de septiembre de 2008, acordó la entrega a las autoridades italianas sin condicionar la entrega a la celebración de un nuevo juicio en Italia ${ }^{24}$. Por providencia dictada cuatro días más tarde, la Sala rechazó la nulidad de actuaciones que el recurrente había solicitado. Al admitir a trámite la demanda de amparo (providencia de 18 de septiembre de 2008), el Tribunal Constitucional acordó suspender la ejecución del Auto de la Audiencia Nacional de 12 de septiembre de 2008. En su demanda de amparo el recurrente sostiene que esta situación implica una vulneración de su derecho a un proceso con todas las garantías (art. 24.2 CE). El Auto de la Audiencia Nacional contra el que se dirige constituye, según su parecer, «una vulneración indirecta de las exigencias absolutas dimanantes del derecho proclamado en el mencionado art. 24.2 CE, al menoscabar el contenido esencial del proceso justo de una manera que afecta a la dignidad humana pues acceder a la extradición a países que, en caso de delito muy grave, den validez a las condenas en ausencia, sin someter la entrega a la condición de que el condenado pueda impugnarlas para salvaguardar sus derechos de defensa, constituye una vulneración del derecho a un proceso con todas las garantías» ${ }^{25}$.

Constitucional sobre la Orden Europea de Detención y Entrega (2004-2010)», en Cardona Llorens, J., et al. (Eds.), Estudios de Derecho internacional y Derecho europeo en homenaje al profesor Manuel Pérez González, Tomo II, Valencia, Tirant, 2012, pp. 1773-1795.

23 Para un análisis, en profundidad, de las diversas cuestiones que encierra este Auto, véanse, entre otros, Huelin Martínez De Velasco, J., «Las implicaciones constitucionales del incumplimiento del deber de plantear cuestión prejudicial ante el Tribunal de Justicia de la Unión Europea (Una aproximación «post-Lisboa)»», REDE, 39, 2011, pp. 375 y ss.; ANDrés SÁEz De SANTA María, P., «Un nuevo paso en el diálogo judicial europeo: el Tribunal Constitucional recurre al reenvío prejudicial», en Fernández Liesa, C.; Moreiro, C.J.; Menéndez ReXach, E. (Dirs.), Libro bomenaje a Dámaso Ruiz-Jarabo, Madrid: CGPJ-Universidad Carlos III, 2011, pp. 189-214; Arroyo JimÉneZ, L., «Sobre la primera cuestión prejudicial planteada por el Tribunal Constitucional. Bases, contenido y consecuencias», WP IDEIR, 8, 2011; MAESO SECO, L.F., «Sobre el régimen jurídico de la cuestión prejudicial tras el Tratado de Lisboa y el ATC 86/2011, de 9 de junio», Justicia Administrativa, 55, 2012, pp. 7 y ss.; RevenGa SÁNCHEZ, M., «Rectificar preguntando. El Tribunal Constitucional acude al Tribunal de Justicia (ATC 86/2011, de 9 de junio)», REDE, 2012, pp. 19 y ss.; GIPPINI-FourNIER, E., «¿Fin de la «autarquía jurídica» o preludio de un conflicto anunciado? El primer reenvío prejudicial del Tribunal Constitucional», Gaceta Jurídica de la Unión Europea y de la Competencia, pp. 5 y ss.; UGARTEMENDIA, J.I. y Ripol Carulla, S., Continuismo y ¿novedad? en la doctrina del Tribunal Constitucional sobre el Derecho de la Unión Europea, Working Paper IDEIR, (Papeles de Derecho Europeo e Integración Regional/Working Papers on European Law and Regional Integration), 12, 2012; ToRres, A., «Constitutional Dialogue on the European Arrest Warrant: The Spanish Constitutional Court Knocking on Luxembourg's Door; Spanish Constitutional Court, Order of 9 June 2011, ATC 86/20111», European Constitutional Law Review, 8, 2012, pp. 105-127.

24 La Audiencia Nacional estimó que el derecho de defensa de Stefano Melloni se había respetado, puesto que era conocedor de la futura celebración del juicio, se había situado voluntariamente en rebeldía y había designado a dos abogados para su representación y defensa, los cuales intervinieron, en esa calidad, en primera instancia, en apelación y en casación, agotando así las vías de recurso.

25 ATC 86/2011, antecedente 3. 
En este contexto procesal, el TC aprueba su Auto 86/2011, de 9 de junio, mediante el que plantea por primera vez una cuestión prejudicial (en realidad son tres) al Tribunal de Justicia. Las dos primeras cuestiones formuladas por el TC se centran en el apartado 1 del nuevo artículo 4.bis de la DM. La argumentación previa esgrimida para plantear la primera prejudicial reconoce que el art. 4 bis de la Decisión Marco impide denegar la ejecución de la OEDE en el caso enjuiciado, pues ahora no se cumple el requisito de falta de conocimiento por el afectado de la celebración del juicio establecido por dicho artículo. Pero el TC, cuyo objetivo es conciliar su doctrina sobre la vulneración indirecta de los DF con el tenor literal de este artículo, pregunta al Tribunal de Justicia si puede entenderse que: aunque la Decisión Marco impide denegar la entrega, permite su condicionamiento. Abundando en este esfuerzo por conciliar su doctrina, más garantista, con la normativa recogida en la Decisión Marco, el TC plantea al Tribunal de Luxemburgo una segunda prejudicial, en concreto sobre la compatibilidad del art. 4 bis, apartado 1, de la Decisión Marco con el sistema de protección de derechos fundamentales de la UE. El TC se refiere expresamente a los derechos a la tutela judicial efectiva y a los derechos de la defensa: artículos 47 y 48 CDFUE, configurando lisa y llanamente como una prejudicial de validez del citado art. 4. bis de la Decisión Marco. Y para el caso de que no prosperaran las anteriores prejudiciales el TC formula, en la misma línea de conciliación, una tercera centrada en el crucial artículo 53 de la Carta de DFUE, del que ofrece diversas interpretaciones, siendo la que más prefiere la de interpretarlo como una cláusula de estándar mínimo de protección, que permitiría desplazar la protección de los Derechos Fundamentales ofrecida por la UE a favor de la protección constitucional interna en aquellos casos en los que esta última sea mayor (una segunda modalidad sería la de asumirla como un instrumento para delimitar el ámbito de aplicación de la Carta; y finalmente, una tercera que pasa por una forma mixta o de integración de las dos anteriores).

La respuesta del Tribunal de Justicia a la primera prejudicial ${ }^{26}$ consistirá en que la autoridad judicial sólo puede supeditar o condicionar la ejecución de una orden de detención europea a los requisitos establecidos en la Decisión Marco, entendiendo a este respecto que el ya mencionado nuevo artículo 4 bis [apartado 1, letras a) y b)] de la misma se opone a que el Juez nacional deniegue la ejecución de una euroorden emitida para el cumplimiento de una pena cuando el interesado no compareció en el juicio pero tuvo conocimiento de la celebración prevista de éste y dio mandato a un letrado para que le defendiera y fue efectivamente defendido por él; situación que, precisamente, acontece con el Sr. Melloni en el presente asunto. Y en esta línea, para el Tribunal, el texto, la estructura y la finalidad de esa disposición se oponen a que la autoridad judicial española someta la ejecución de una orden de detención europea a la condición de que la condena impuesta en rebeldía pueda ser revisada en Italia, Estado miembro emisor de la orden de detención ${ }^{27}$.

La contestación a la segunda prejudicial establecerá que aquella disposición de la Decisión Marco es compatible con el derecho a la tutela judicial efectiva y a un proceso equitativo y con el derecho de defensa reconocidos en los artículos 47 y 48.2 de la Carta de DFUE. Y ello sobre la base de que, aunque el derecho del acusado a comparecer en el jui-

26 Siguiendo aquí, al igual que en las otras cuestiones prejudiciales del caso, las Conclusiones que el Abogado General Yves Bot hizo públicas el 2 de octubre de 2012 a este asunto C-399/11.

27 Apartados 40 y ss. de la Sentencia. 
cio constituye un elemento esencial del derecho a un proceso equitativo, dicho derecho no es absoluto, puesto que el acusado puede renunciar a él, expresa o tácitamente, con ciertas garantías. Y la disposición mencionada enuncia las condiciones en las que se considera que el interesado ha renunciado voluntariamente y de forma inequívoca a comparecer en su juicio, entre las que se encuentra la de conferir mandato a un letrado para que le defienda en el juicio en el que no ha comparecido, condición que según el Tribunal concuerda con el alcance reconocido a los derechos garantizados en el art. 6, apartados 1 y 3, del CEDH y por la jurisprudencia del Tribunal Europeo de Derechos Humanos ${ }^{28}$.

Finalmente, el Tribunal resolverá ante la tercera cuestión que el artículo 53 de la Carta de DFUE tampoco puede ser interpretado en el sentido de que permite que un Estado miembro subordine la entrega de una persona condenada en rebeldía a la condición de que la condena pueda ser revisada en el Estado miembro emisor, para evitar una vulneración del derecho a un proceso con todas las garantías y de los derechos de la defensa protegidos por su Constitución. Y ello porque aceptar esta interpretación, esto es, interpretar que cabe establecer esa condición no prevista en la Decisión Marco para evitar la lesión de un derecho fundamental a la luz del estándar nacional de protección del mismo «conduciría, al poner en cuestión la uniformidad del nivel de protección de los derechos fundamentales definido por esa Decisión marco, a contravenir los principios de confianza y de reconocimiento mutuo, que ésta pretende reforzar, y por consiguiente a comprometer la efectividad de la referida Decisión marco» ${ }^{29}$. Y es que, como señala el Tribunal en un parágrafo nuclear de la Sentencia sobre el que volveremos más adelante, «es cierto que el artículo 53 de la Carta confirma que, cuando un acto del Derecho de la Unión requiere medidas nacionales para su ejecución, las autoridades y tribunales nacionales siguen estando facultados para aplicar estándares nacionales de protección de los derechos fundamentales siempre que esa aplicación no afecte al nivel de protección previsto por la Carta, según su interpretación por el Tribunal de Justicia, ni a la primacía, la unidad y la efectividad del Derecho de la Unión» ${ }^{30}$.

\section{(B) El PROBLEMA-DILEMA DEL PARÁMETRO IUSFUNDAMENTAL}

¿Debe enfocarse la tutela de los derechos fundamentales ante una actividad estatal realizada en aplicación del Derecho de la Unión ${ }^{31}$, necesaria y exclusivamente, desde el sistema de los DFUE, o hay un margen para utilizar estándares nacionales de protección de los DF? ¿Y si lo hay, con qué límites? El asunto Melloni nos muestra dos distintas for-

28 Apartados 49 y ss. de la Sentencia.

29 Apartado 63 de la Sentencia.

30 Ibidem, apartado 60. Para un análisis en profundidad de la Sentencia véase, por ejemplo: UGARTEmendia, J.I. y Ripol Carulla, S., «La Euroorden ante la tutela de los Derechos Fundamentales. Algunas cuestiones de soberanía iusfundamental (A propósito de la STJ Melloni, de 26 de febrero de 2013, C-399/11)» en REDE, 46, 2013, pp. 151-197. Díez-Hochleitner, J., «El derecho a la última palabra: ¿Tribunales constitucionales o Tribunal de Justicia de la Unión?», en Papeles de Derecho Europeo e Integración Regional, WP IDEIR, 17, 2013. Torres Muro, I. «La condena en ausencia: unas preguntas osadas (ATC 86/2001, de 9 de junio) y una respuesta contundente (Sentencia del Tribunal de Justicia de la Unión Europea de 26 de febrero de 2013)», Revista Española de Derecho Constitucional, n. ${ }^{\circ}$ 97, 2013, pp. 343-370.

31 En este caso, ante una resolución judicial que aplica una euroorden de entrega para cumplimiento de condena. 
mas de enfocar y responder estas interrogantes: la de la Sentencia Melloni, de 26 de febrero de 2013, y la del Auto del TC del que ésta deriva: el Auto 86/2011, de 9 de junio.

La lectura del Auto 86/2011 permite observar que el TC maneja una regla según la cual los DFUE deben funcionar como parámetro de legalidad tanto de la actividad normativa de las instituciones europeas como de la aplicación interna del Derecho de la Unión. Ahora bien, el Auto deja claro que esa función de parámetro es distinta en función de si se predica (a) frente a la actividad de las instituciones, en este caso, de la Decisión Marco relativa la euroorden, o si (b) por el contrario, se alza en relación a la actividad interna de aplicación del Derecho de la Unión, en nuestro caso, ante una actuación judicial de ejecución de una orden de detención y entrega. Y es que, la resolución del Tribunal Constitucional reconoce, por una parte, que los derechos de la Carta actúan como parámetro de enjuiciamiento de «europeidad» de la actividad institucional europea (de la conformidad de la DM con el Derecho originario de la Unión). De hecho, la segunda cuestión es, lisa y llanamente, una prejudicial de validez. Pero por otra parte, el ATC sostiene que, respecto a la actividad de aplicación nacional del Derecho de la Unión, los DFUE actúan como canon indirecto de «constitucionalidad».

De forma más precisa, para el ATC, la cuestión suscitada en el presente proceso de amparo consiste en dirimir «si la resolución de entrega vulneró o no indirectamente el derecho a un proceso con todas las garantías tal y como éste resulta protegido por la Constitución española (art. 24.2 CE)», entendiendo que, en este contexto, el Derecho de la Unión y la Carta de DFUE (leo textualmente) han de «tenerse en cuenta a la hora de integrar el canon de constitucionalidad relevante», como «criterio de integración del contenido del derecho reconocido en el art. 24.2 CE». De manera que, para el TC, en el contexto del presente caso, los DFUE actúan como «parámetro indirecto de la constitucionalidad» del acto nacional de aplicación del Derecho de la Unión, en este caso de la resolución judicial de la Audiencia Nacional.

La Sentencia Melloni del TJ, sin embargo, deja sentada de una forma clara, categórica, la idea de que es el estándar europeo de los Derechos Fundamentales el que debe funcionar como parámetro de enjuiciamiento de la resolución judicial nacional, en concreto, el estándar establecido, de acuerdo con la Carta y el Convenio, en la propia Decisión Marco en relación a los derechos procesales de las personas condenadas en rebeldía contra las que se emite una orden de detención y entrega europea. Y es en esta diferente manera de concebir la tutela de los DF en el ámbito interno o nacional (en el que se aplica Derecho de la Unión) donde surge la diferencia entre los dos Tribunales

En efecto, ni el Auto del TC ni, obviamente, tampoco la Sentencia Melloni del Tribunal de Justicia, niegan u olvidan la función de canon de enjuiciamiento directo que juegan los DFUE sobre la Decisión Marco (relativa a la euroorden), si bien es cierto que el Tribunal Constitucional duda —en la $2 .^{\circ}$ prejudicial- de su validez (en concreto, con respecto a los arts. 47 y 48 de la Carta) y el Tribunal de Justicia, en cambio, la confirma. Es verdad, pues, que hay disenso a la hora de contrastar la Decisión Marco con la Carta, pero no sobre su uso como canon directo de enjuiciamiento. Sin embargo, como decimos, ambos Tribunales se diferenciarán de forma clara en el modo de entender el rol que deben jugar los Derechos de la Carta en el ámbito nacional, a la hora de aplicar el Derecho de la Unión. Un rol de constitucionalidad interna (canon indirecto 
de constitucionalidad) para el ATC, un rol de europeidad (o como canon de Derecho de la Unión) para el Tribunal de Luxemburgo.

Pero, mirando la cuestión con más perspectiva, parece evidente que este disenso va todavía más allá. Al final, lo que se tercia en este asunto entre los dos Tribunales «no es sólo como entender la Carta de los DFUE, sino también cuál debe ser el estándar de protección de los Derechos Fundamentales que actúa en el orden interno cuando se aplica Derecho de la Unión: si el estándar nacional (el establecido por la Constitución nacional), abierto a la Unión a través de la cláusula del 10.2, pero «nacional» a la postre, o el estándar europeo, el que asume los DFUE como canon directo de Derecho europeo.

El Tribunal de Justicia resolverá en Melloni, como ya hemos tenido ocasión de apuntar, que, obviamente, debe primar el estándar iusfundamental europeo: no cabe que la resolución judicial nacional condicione la ejecución de la euroorden a que se garantice una revisión de la condena para salvar así el entendimiento nacional de los derechos de defensa. La DM que impide esa posibilidad ya es, pese a todo, conforme a la Carta y al Convenio. Sin embargo, el Tribunal de Justicia no se quedará simplemente ahí. Lo interesante de esta decisión es que, no sólo resuelve este asunto concreto, sino que establece además, de forma combinada (o conjunta) con la Sentencia Akerberg, dictada en la misma fecha, una regla general que aclara y precisa un poco más cómo debe tratarse esta cuestión de la tutela de los DF cuando se aplica Derecho de la Unión, distinguiendo (para ello) dos diferentes situaciones.

\section{III.1.2 La solución: la «regla de las situaciones iusfundamentales (la situación Melloni y la situación Akerberg)»}

En lo que sigue voy a tratar de describir esa regla general, pero antes realizaré pero antes conviene apuntar una brevísima contextualización evolutiva de la jurisprudencia del TJ sobre la aplicabilidad interna de los DFUE con objeto de valorar mejor dicha regla y sus implicaciones. Hace ya casi 25 años desde que, con la sentencia Wachauf del año 89, el Tribunal reconoció la obligación de respetar los DFUE que tiene el poder público nacional cuando actúe en el ámbito de aplicación del Derecho de la Unión. A lo largo de estos cinco lustros, la jurisprudencia del Tribunal ha ido detallando, señalando y matizando, como ha quedado apuntado al comienzo de estas páginas, qué actividad estatal entra »dentro» de ese ámbito de aplicación nacional y, por tanto, de respeto de los DFUE. Ahí está la ya larga progenie jurisprudencial de la resolución Wachauf al respecto $^{32}$. Y ahí también, tal y como igualmente se ha señalado, el artículo 51.1 de la Carta de los DFUE aprobada el año 2000, que ha adquirido fuerza jurídica vinculante hace cuatro años, formalizando toda esa jurisprudencia sobre la obligada (comunitariamente obligada) incorporación nacional de los DFUE.

32 De 18 de junio de 1991, as. ERT, C-260/89; de 26 de mayo de 1997, as. Familiapress, C-368/95; de 12 de junio de 2003, as. Schmidberger, C-112/00, de 14 de octubre de 2004, as. Omega, C-36/02; de 16 de junio de 2005, as. Pupino, C-105/03; de 11 de diciembre de 2007, as. Viking, C-438/05; de 18 de diciembre de 2007, as. Laval, C-341/05; de 8 de marzo de 2011, as. Ruiz Zambrano, C-34/09; de 12 de mayo de 2011, as. Sayn-Wittgenstein, C-208/09; entre otras. 
No obstante, se podría decir que la mayoría de todos estos hitos jurisprudenciales sobre la aplicabilidad interna de los DFUE se ha dedicado a analizar y delimitar la «extensión» del ámbito de aplicación interna de los mismos, esto es, a señalar una especie de mapa del mismo, concretando qué actuación estatal entra y cuál no en ese radio o campo de acción interno donde esos derechos son de obligado respeto. Y en cambio, en realidad, el Tribunal nunca se ha detenido a resolver la cuestión de la «intensidad» o la profundidad de ese vínculo u obligación nacional de respetar la Carta «dentro» ya del ámbito de aplicación. De esta manera, siempre ha permanecido latente, y los asuntos Melloni y Akerberg son una buena prueba de ello, la cuestión de si, dentro de ese ámbito de aplicación, «cabe también», y con qué margen, utilizar como canon de enjuiciamiento los derechos reconocidos por la Constitución nacional, especialmente si la conexión entre acto nacional y Derecho de la Unión es débil. Es más, siempre se ha actuado como si ese uso del sistema iusfundamental nacional fuera compatible/compaginable con el sistema de los DFUE, especialmente si utilizamos cláusulas de apertura constitucional iusfundamental como la del 10.2 CE. En otras palabras, siempre ha permanecido vigente e irresuelta la cuestión de hasta qué puede operar el sistema nacional de los DFUE supliendo o de manera compaginada con el sistema europeo-comunitario.

Pues bien, lo interesante de Melloni y Akerberg es que vienen a dar una respuesta a esta dimensión del problema, constituyendo otro hito jurisprudencial importante en la recepción y aplicabilidad nacional de los DFUE, en este caso porque inciden y profundizan sobre algunos rasgos de la obligación de respeto que se les debe en el ámbito nacional. Dichas sentencias confirman categóricamente que los DFUE son el parámetro o canon de enjuiciamiento en el ámbito nacional de aplicación del Derecho de la Unión, pero reconocen, por primera vez, de forma clara una regla o pauta que dirime cuándo y en qué condiciones puede actuar «también» el sistema nacional de protección de los DF dentro del ámbito delimitado por la aplicación interna del Derecho de la Unión, y por tanto de forma compatible con los DFUE. La regla que cabe inferir, de forma idéntica, de ambas Sentencias, es una regla que contempla dos situaciones (iusfundamentales) diferentes, cada una con su consecuencia. Según establece la misma —una regla que el Tribunal entiende «confirmada» por el artículo 53 de la Carta— «cuando un acto del Derecho de la Unión requiere medidas nacionales para su ejecución, las autoridades y tribunales nacionales siguen estando facultados para aplicar estándares nacionales de protección de los derechos fundamentales, siempre que esa aplicación no afecte al nivel de protección previsto por la Carta, según su interpretación por el Tribunal de Justicia, ni a la primacía, la unidad y la efectividad del Derecho de la Unión» ${ }^{33}$, mientras que - cabe deducir a sensu contrario-, cuando la aplicación nacional del Derecho de la Unión deba realizarse sin margen para adoptar aquellas medidas normativas internas, no habrá otra posibilidad que aplicar el estándar iusfundamental de la Unión. Si ésta situación se da en el asunto Melloni, aquella, por el contrario, aparece escenificada en el asunto Akerberg. Veámoslo de forma un poco más detenida.

33 Regla recogida en el apartado 60 de la Sentencia Melloni, que se ve reiterada, como veremos más adelante, en el apartado 29 de la Sentencia Akerberg. 


\section{(A) La Situación MELlONi}

Por una parte, la «situación Melloni», que es la que se genera cuando un acto del Derecho de la Unión no requiera medidas nacionales para su ejecución, porque la regulación está totalmente detallada o determinada.

Pues bien, el Tribunal deja entender que en este supuesto, no hay margen para utilizar estándares nacionales de protección de los DF ante la actuación interna. Ésta era la ya descrita situación del asunto Melloni, pues el art. 4 bis DM, en su versión de 2009, ya regula — de manera conforme a la Carta y el Convenio-todo lo relativo a los derechos procesales de las personas en cuanto al reconocimiento de las resoluciones dictadas a raíz de juicios sin comparecencia del imputado ${ }^{34}$. De manera que, en este caso, no hay margen para (introducir particularidades nacionales como) condicionar la entrega (al hecho de que se asegure la revisión de la condena en Italia) y salvar así la vulneración indirecta del art. $24 \mathrm{CE}$, pues ello va contra la uniformidad y efectividad de una DM). En la situación Melloni, no hay margen para juzgar la resolución judicial de entrega bajo el estándar iusfundamental nacional, se eche mano o no del art. 10.2 CE (apertura constitucional al Derecho supranacional e internacional de los Derechos humanos, incluido el de los DFUE).

\section{(B) La situación Akerberg}

La otra situación contemplada, ésta de forma explícita, es la «situación (del caso) Akerberg» ${ }^{35}$, la que se da, a diferencia de Melloni, cuando el acto de la Unión requiere medidas de ejecución, esto es, cuando la actuación de aplicación estatal no esté totalmente determinada o armonizada. La Sentencia Akerberg, por lo que ahora interesa destacar, trae causa de una remisión prejudicial de un Tribunal sueco, planteando, entre otras cuestiones prejudiciales, si es posible entablar una acción penal por infracción fiscal contra una persona a la que ya se ha impuesto un recargo fiscal por los mismos hechos de declaraciones fiscales falsas en materia de IVA, de acuerdo con el derecho fundamental a no ser inculpado o sancionado «penalmente» dos veces por la misma infracción (principio non bis in idem) reconocido en el artículo 50 de la Carta ${ }^{36}$. Entre las observaciones presentadas en el caso por algunas de las partes interesadas se alegará la inadmisibilidad de las cuestiones prejudiciales, señalando que el Tribunal sólo podría ser competente si los mencionados recargos fiscales impuestos y la acción penal ejercitada contra el Sr. Akerberg se debieran a una aplicación del Derecho de la Unión. Pero ni la norma nacional con arreglo a la cual se impusieron los recargos fiscales, ni la legislación en la que se basa la acción penal, constituyen, para la parte alegadora, una aplicación del Derecho de la Unión. Y en consecuencia, se considera que, conforme al artículo 51.1 de la Carta de DFUE (artículo que delimita el ámbito de aplicación de la

34 Véanse al respecto, por ejemplo: los apartados 59 y ss. de la Sentencia y 67 y ss. de las Conclusiones del Abogado General.

35 STJ de 26 de febrero de 2013, as. Hans Akerberg Fransson (C-617/10).

36 Artículo 50: «Derecho a no ser juzgado o condenado penalmente dos veces por la misma infracción: Nadie podrá ser juzgado o condenado penalmente por una infracción respecto de la cual ya haya sido absuelto o condenado en la Unión mediante sentencia penal firme conforme a la ley». 
Carta) $)^{37}$, esos recargos fiscales y la acción penal señalada no están incluidos en el ámbito de aplicación del principio non bis in idem garantizado por el artículo 50 de la Carta. El Abogado General P. Cruz Villalón considerará, de forma similar, que nos encontramos ante «un supuesto no regido por la situación "aplicación del Derecho de la Unión"”, dado que el grado de conexión en el caso entre el Derecho de la Unión y el ejercicio de la potestad pública (sancionadora) del Estado es «debilísima, no siendo en todo caso suficiente para fundamentar un interés claramente identificable de la Unión en asumir la garantía de este concreto derecho fundamental hacia la Unión $»^{38}$, de manera que el TJ no debe apreciar el caso como un supuesto de aplicación del Derecho de la Unión en el sentido del art. 51.1 de la Carta ${ }^{39}$.

Frente a ello, sin embargo, el Tribunal de Justicia, recordará, en primer lugar, que la actividad de los Estados está vinculada por la Carta y las exigencias derivadas de los derechos de la misma «cuando apliquen Derecho de la Unión», tal y como se refleja en el mencionado artículo $51.1^{40}$ y en las explicaciones relativas al mismo ${ }^{41}$. Y que, en consecuencia, «no existe ningún supuesto comprendido en el Derecho de la Unión en el que no se apliquen dichos derechos fundamentales. La aplicabilidad del Derecho de la Unión implica la aplicabilidad de los derechos fundamentales garantizados por la Carta ${ }^{42}$. Una vez repasada la doctrina, señalará, en segundo lugar, que los recargos fiscales impuestos al Sr. Hans Akerberg y la acción penal ejercitada contra él se deben en parte al incumplimiento de sus obligaciones declarativas en materia de IVA (la inexactitud de la información proporcionada en dicha materia), y que por ello «constituyen una aplicación de los artículos 2, 250, apartado 1, y 273 de la Directiva 2006/112 (anteriormente artículos 2 y 22 de la Sexta Directiva) y del artículo 325 TFUE, y por lo tanto del Derecho de la Unión en el sentido del artículo 51, apartado 1, de la Carta» ${ }^{43}$. Y tras identificar así el ámbito de aplicación interna del Derecho europeo, volverá a resaltar, de forma muy similar a como lo hizo en la Sentencia Melloni, la regla de que «cuando un órgano jurisdiccional de un Estado miembro deba controlar la conformidad

37 «Las disposiciones de la presente Carta están dirigidas a las instituciones, órganos y organismos de la Unión, dentro del respeto del principio de subsidiariedad, así como a los Estados miembros únicamente cuando apliquen el Derecho de la Unión. Por consiguiente, éstos respetarán los derechos, observarán los principios y promoverán su aplicación, con arreglo a sus respectivas competencias y dentro de los límites de las competencias que los Tratados atribuyen a la Unión» (énfasis añadido).

38 Apartado 57 de las Concusiones del AG P. Cruz Villalón, de 12 de junio de 2012, as. H. Akerberg, C-617/10.

39 Apartado 64 de las Conclusiones.

40 Artículo que viene a confirmar su jurisprudencia, clásica y reciente, en la materia, según se encarga de recordar de forma detallada el propio Tribunal en el apartado 19 de la sentencia.

41 Y debe recordarse que, según dispone el artículo 52.7 de la Carta: «Las explicaciones para guiar la interpretación de la presente Carta serán tenidas debidamente en cuenta por los órganos jurisdiccionales de la Unión y de los Estados miembros».

42 Apartado 21.

43 Apartado 27 de la Sentencia. Se refiere en concreto a de la Directiva 2006/112/CE del Consejo, de 28 de noviembre de 2006, relativa al sistema común del impuesto sobre el valor añadido («DO» L 347, p. 1), de la que se deriva que cada Estado miembro tiene la obligación de adoptar todas las medidas legislativas y administrativas necesarias para garantizar que el IVA se perciba íntegramente en su territorio y para luchar contra el fraude. El artículo 325 TFUE, por su parte, exige a los Estados miembros que combatan las actividades ilegales que afecten a los intereses financieros de la Unión mediante medidas disuasorias y efectivas. 
con los derechos fundamentales de una disposición o de una medida nacional por la que se aplica el Derecho de la Unión en el sentido del artículo 51, apartado 1, de la Carta, en una situación en la que la acción de los Estados miembros no esté totalmente determinada por el Derecho de la Unión, las autoridades y tribunales nacionales siguen estando facultados para aplicar estándares nacionales de protección de los derechos fundamentales, siempre que esa aplicación no afecte al nivel de protección previsto por la Carta, según su interpretación por el Tribunal de Justicia, ni a la primacía, la unidad y la efectividad del Derecho de la Unión (véase, en este sentido, la sentencia de 26 de febrero de 2013 , Melloni, C-399/11, Rec. p. I-0000, apartado 60)» ${ }^{44}$.

Y para el TJ la situación del caso Akerberg es precisamente esa en la que - a diferencia de lo que ocurre en una situación como la del caso Melloni- la actuación del Estado miembro, aunque tiene su origen o entra en el ámbito de aplicación del Derecho de la Unión ${ }^{45}$, no está totalmente regulada o armonizada por éste Derecho (en este caso, a la hora de establecer la potestad sancionadora del Estado para evitar el fraude contra el IVA y combatir contra las actividades ilegales que afecten a los intereses financieros de la Unión). De manera que el Juez sueco del caso podrá seguir aplicando los estándares nacionales de protección de los Derechos Fundamentales (sin dejar de ser Juez nacional que actúa como Juez comunitario). Pero, eso sí, bajo dos condiciones aceradas: (b.1) que esa aplicación no afecte al nivel de protección previsto por la Carta, según su interpretación por el Tribunal de Justicia, de manera que la Carta sigue siendo una referencia iusfundamental incondicionada; (b.2) y que tampoco afecte a la primacía, la unidad y la efectividad del Derecho de la Unión ${ }^{46}$.

Y en esta línea, es evidente que mientras aquél primer requisito impedirá que el ordenamiento interno pueda ser entendido, utilizado o esgrimido para rebajar el nivel

44 Apartado 29 (énfasis añadido). En el mencionado apartado 60 de la STJ Melloni el Tribunal se referirá a la existencia de esas mismas facultades (condicionadas) «cuando un acto del Derecho de la Unión requier[a] medidas nacionales para su ejecución».

45 Cfr. apartados 27 y 28 de la Sentencia.

46 Hay que destacar, en cualquier caso, que la Sentencia Akerberg ya ha comenzado a ser objeto de discusión y de cuestionamiento. En efecto, el Tribunal Constitucional Federal Alemán ya ha emitido una Sentencia (de 24 de abril de 2013, 1 BvR 1215/07; relativa a las bases de datos contra el terrorismo) en la que enfoca un caso similar de forma contraria a como lo hace el TJ en aquella, viniendo a tratar de limitar (expresamente) su alcance. Como se resume en el segundo apartado de la nota de prensa oficial de la misma, el Tribunal Constitucional alemán, partirá de la base de que la Ley sobre bases de datos contra el terrorismo — norma sobre cuya compatibilidad constitucional versa la resolución-y las actuaciones basadas en la misma no constituyen una implementación del Derecho de la Unión en los términos del artículo 51.1 de la Carta de DFUE. Para el Tribunal «the Counter-Terrorism Database Act pursues nationally determined objectives which can affect the functioning of the legal relationships under EU law merely indirectly. Thus, the European fundamental rights are from the outset not applicable, and the European Court of Justice is not the lawful judge according to Art. $101 \mathrm{sec} .1$ sentence 2 of the Basic Law (Grundgesetz - GG). The European Court of Justice's decision in the case Åkerberg Fransson (judgment of 26 February 2013, C-617/10) does not change this conclusion. As part of a cooperative relationship, this decision must not be read in a way that would view it as an apparent ultra vires act or as if it endangered the protection and enforcement of the fundamental rights in the member states in a way that questioned the identity of the Basic Law's constitutional order. The Senate acts on the assumption that the statements in the ECJ's decision are based on the distinctive features of the law on valueadded tax, and express no general view. The Senate's decision on this issue was unanimous» (http://www. bundesverfassungsgericht.de/pressemitteilungen/bvg13-031en.html; para el texto complete de la Sentencia: http://www.bundesverfassungsgericht.de/ entscheidungen/rs20130424_1bvr121507.html). 
de protección de la Carta (y/o de los DFUE entendidos como principios generales del Derecho $)^{47}$, el segundo, a su vez, actuará de forma incisiva - como ha ocurrido en el asunto Melloni- para impedir que una tutela iusfundamental nacional más extensa o ambiciosa que la europea termine minando aquellos rasgos de primacía, unidad y efectividad del Derecho de la Unión (lo cual no quiere decir, obviamente, que se impide una tutela iusfundamental nacional más extensa que la europea en el ámbito de aplicación del Derecho de la Unión, sino que lo que se pretende evitar que esa mayor tutela lo sea a expensas de estos rasgos vitales del Derecho de la Unión). De cualquier manera, da la impresión de que se ha estipulado un nuevo hito jurisprudencial (Mellonil Akerberg), que a buen seguro — como hemos apuntado — ha comenzado ya a ser discutido, pero que será necesario tener en cuenta en buena parte de los nuevos y muchos casos que irán surgiendo sobre la aplicabilidad de los Derechos Fundamentales en el ámbito de aplicación nacional del Derecho de la Unión (especialmente los ligados al Espacio de Libertad, Seguridad y Justicia, y sobre todo en el ámbito de la cooperación policial y judicial penal). Piénsese, por ejemplo, por apuntar algunos significativos casos de muy reciente planteamiento: en el asunto Seitlinger y otros, en el que el Tribunal Constitucional austriaco plantea su primera petición prejudicial, el 28 de noviembre de 2012 (C-594/12) ${ }^{48}$; o en la primera cuestión prejudicial (de urgencia o PPU) planteada por el

47 Puede ser interesante recordar, en este contexto, situaciones en las que, justo al contrario de lo que sucede en Melloni (donde está en juego que el Estado miembro quiere aplicar un estándar de protección de unos derechos fundamentales — art 24.2 CE— más alto que el europeo — arts. 47 y 48.2 de la Carta-, entrando en conflicto con la eficacia y uniformidad del Derecho de la Unión), la Unión pretenda realizar una protección de los Derechos Fundamentales más amplia o intensa de la que realiza el ordenamiento interno. Supuesto en el que no se podrá esgrimir, por parte del Estado, la suficiencia de ese estándar inferior, aunque haya sido afirmada por el propio Tribunal Constitucional, como quedó evidenciado en la STJ al asunto Anacleto Cordero (de 7 de septiembre de 2006, C-81/05). En esta Sentencia el Tribunal de Luxemburgo estableció, en «contra» de lo previamente estipulado al respecto por el TC español (STC 306/1993, de 25 de octubre de 1993, en la que se confirmaba la constitucionalidad ex 14 CE de la regulación española —art. 33.2 del Estatuto de los Trabajadores - relativa al régimen indemnizatorio del FOGASA en caso de insolvencia del empresario), que las indemnizaciones legales debidas por la finalización del contrato de trabajo reconocidas en un acuerdo entre trabajador y empresario celebrado en presencia judicial y con la aprobación del órgano judicial deben recibir el mismo trato que las establecidas por sentencia judicial (el TC, por el contrario, había constatado que el trato diferenciado entre unas y otras establecido según el citado 33.2 no vulneraba el artículo $14 \mathrm{CE}$ por cuanto no existe un tratamiento diferenciado de situaciones idénticas). [Véase, al respecto, por ejemplo: SARAZÁ JIMENA, R., «Primacía del Derecho comunitario, derechos fundamentales y sistema constitucional español (comentario a la STJCE de 7 de septiembre de 2006, asunto C-81/05, caso Cordero Alonso)», Revista Poder Judicial, núm. 82, 2006, pp. 11 y ss.].

48 Una petición de decisión prejudicial — del Verfassungsgerichtshof — donde, además de una prejudicial de validez, a la luz de los artículos 7, 8 y 11 de la Carta de los Derechos Fundamentales de la Unión Europea, de los artículos 3 a 9 de la Directiva 2006/24/CE del Parlamento Europeo y del Consejo, de 15 de marzo de 2006, sobre la conservación de datos generados o tratados en relación con la prestación de servicios de comunicaciones electrónicas de acceso público o de redes públicas de comunicaciones y por la que se modifica la Directiva 2002/58/CE («DO»L 105, p. 54), se plantean también diversas cuestiones sobre la interpretación de la Carta de los Derechos Fundamentales de la Unión Europea y, en particular, de sus artículos 7, 8, 52 y 53 en relación a la Directiva 95/46/CE del Parlamento Europeo y del Consejo, de 24 de octubre de 1995, relativa a la protección de las personas físicas en lo que respecta al tratamiento de datos personales y a la libre circulación de estos datos ( «DO» L 281, p. 31), y al Reglamento (CE) n. ${ }^{\circ}$ 45/2001 del Parlamento Europeo y del Consejo, de 18 de diciembre de 2000 , relativo a la protección de las personas físicas en lo que respecta al tratamiento de datos personales por las instituciones y los organismos comunitarios y a la libre circulación de 
Consejo Constitucional francés, el pasado 4 de abril de 2013, en relación a la interpretación de los artículos 27 y 28 de la aquí ya mencionada Decisión Marco 2002/584/JAI de 13 de junio de 2002 relativa a la euroorden ${ }^{49}$.

\section{(C) Algunas conclusiones Respecto a las implicaciones De LA REGLA EN EL ORDEN INTERNO}

Esta regla de las (diferentes) situaciones y en general el juego combinado de las resoluciones Melloni-Akerberg permite, aventurar una serie de conclusiones en cuanto a la aplicabilidad de los DF como parámetro de enjuiciamiento de la actividad interna en aplicación del Derecho de la Unión.

En primer lugar, integrando las dos situaciones, puede decirse que, dentro del ámbito de aplicación interna del Derecho de la Unión, no hay margen de actuación para los estándares nacionales de protección si no hay margen de actuación nacional en la ejecución del Derecho de la Unión o, dicho de otra manera, si el acto de aplicación aparece totalmente determinado (como ocurre en Melloni). Y cuando lo haya, (como en Akerberg) aquellos estándares no pueden condicionar ni el nivel de protección de la Carta, ni la primacía, unidad y efectividad del Derecho de la Unión.

En segundo lugar, parece claro que, en el ámbito de aplicación nacional del Derecho de la Unión, y según la mencionada regla, éste Derecho puede llegar a condicionar el sistema nacional de Derechos Fundamentales, siempre que sea conforme a la Carta según es entendida por el TJ, y al Convenio interpretado por el Tribunal de Estrasburgo; y siempre que se respete la identidad constitucional nacional (art. $4.2 \mathrm{TUE})^{50}$. Y por el contrario, ni el ordenamiento interno ni el sistema nacional de derechos pueden ser

estos datos («DO» 2001, L 8, p. 1), dentro del contexto de un Recurso de inconstitucionalidad contra determinadas disposiciones de la Ley federal austriaca de telecomunicaciones, que transpone la Directiva 2006/24/ CE del Parlamento Europeo y del Consejo, de 15 de marzo de 2006, sobre la conservación de datos generados o tratados en relación con la prestación de servicios de comunicaciones electrónicas de acceso público o de redes públicas de comunicaciones (BGBI. I n. ${ }^{\circ}$ 27/2011) Ey también contra la Ley austriaca de enjuiciamiento criminal (en la versión publicada en el BGBI. I n. ${ }^{\circ}$ 33/2011) y la Ley austriaca de la Policía de Seguridad (en la versión publicada en el BGBI. I n. $\left..^{\circ} 33 / 2011\right)$ ].

49 En el marco de una Cuestión prioritaria de constitucionalidad (QPC, establecida, de conformidad con el artículo 61.1 de la Constitución, por la Ley Orgánica n. ${ }^{\circ}$ 2009-1523, de 10 de diciembre de 2009), derivada desde la Corte de Casación en relación a la inconstitucionalidad —en relación al art. 6 de la Declaración de Derecho que protege la igualdad en lo que se respecta al principio de los derechos de defensa — de la ausencia de recurso de apelación en los casos en que se pretendan extender los efectos de una orden de detención europea [en virtud del párrafo cuarto del artículo 695-46 del Código de Procedimiento Penal que transpone al ordenamiento francés el párrafo 4 del mencionado art. 27 y el c) del apartado 3 del artículo 28 de la euroorden].

$50 \mathrm{Tal}$ y como da a entender el Abogado General en los apartado 140 y ss. de sus Conclusiones Generales. Recuérdese que, según el artículo 4.2 del TUE, la Unión deberá respetar la «identidad nacional» (que incluye como una de sus concreciones la «identidad constitucional») de los Estados miembros, «inherente a las estructuras fundamentales políticas y constitucionales de éstos», afirmación que también aparece formulada en el Preámbulo de la Unión, cuando señala que la actividad de ésta debe respetar «la identidad nacional de los Estados miembros». Sobre la cuestión véanse las SSTJ: de 22 de diciembre de 2010, as. Sayn-Wittgenstein (C-208/09), apartado 92; de 12 de mayo de 2011, as. Runevic-Wardyn (C-391/09), apartado 86; y de 24 de mayo de 2011, as. Comisión c. Luxemburgo (C-51/08), apartado 124. Véase, también, el apartado 59 de las conclusiones del Abogado General Jääskinen en el asunto Las (C-202/11, pendiente ante el Tribunal de Justicia). 
esgrimidos para rebajar el nivel de protección de la carta según es entendido por el TJ. Aunque, en la situación Akerberg el juez nacional está facultado para utilizar el estándar nacional de protección de los DF, ese uso facultativo del estándar nacional, no desplaza «nunca» la necesidad u obligación de respetar «siempre» el nivel de la Carta entendido por el TJ (así como la primacía, unidad y efectividad del DUE). La situación Akerberg permite (siempre en el mencionado ámbito de aplicación nacional del Derecho de la UE) una operatividad condicionada del estándar nacional, y confirma que el nivel de protección de los DFUE es siempre un parámetro de referencia indisponible para el juez nacional del caso, pues deberá respetarlo en todo caso.

En este sentido, puede ser interesante traer a colación otra manifestación puntual de esta regla general de la «indisponibilidad nacional» del respeto al Derecho de la Unión y a los DFUE que rige en el ámbito nacional de aplicación del Derecho de la Unión, una manifestación que queda establecida, también en la Sentencia Akerberg, cuando se establece que «el Derecho de la Unión se opone a una práctica judicial que supedita la obligación del juez nacional de no aplicar ninguna disposición que infrinja un derecho fundamental garantizado por la Carta al requisito de que dicha infracción se deduzca claramente del texto de dicha Carta o de la jurisprudencia en la materia, dado que priva al juez nacional de la facultad de apreciar plenamente, con la cooperación del Tribunal de Justicia en su caso, la compatibilidad de dicha disposición con la Carta» ${ }^{51}$. La utilización de la Carta como parámetro de enjuiciamiento no es susceptible de ser sometida a condición a la hora de su aplicación.

En tercer lugar, el juego del art. 10.2 CE como cauce de entrada de los DFUE no suple la obligación de respetar el nivel de protección de la Carta en cuanto Derecho Europeo. La cláusula de apertura constitucional a los DFUE no es operativa en la situación Melloni pues no lo es el estándar nacional (y así lo demuestra, precisamente la Sentencia Melloni), y su uso en la situación Akerberg está condicionado a que se respete, como decimos, el nivel de protección de la Carta pero según es entendida por el TJ. Los derechos constitucionales entendidos desde la apertura constitucional a los DFUE (situación en la que estos juegan de parámetro indirecto de inconstitucionalidad) no pueden desplazar totalmente a los DFUE en cuanto directo parámetro de comunitariedad (únicamente en cuanto no contraríen el nivel de protección marcado por éste)

Y finalmente, debe señalarse que todo lo anterior guarda relación directa con que, como señalan el Tribunal, y antes las Conclusiones del Abogado General, la tutela de los derechos fundamentales debe ser conciliable con los intereses específicos de la Unión. No es lo mismo tener en cuenta los DFUE desde los intereses del ordenamiento interno que considerarlos desde los intereses de la Unión (el sistema nacional de tutela no puede condicionar, aunque esté abierto a la Unión, la primacía, la unidad o la efectividad del Derecho de la Unión). No es lo mismo leer los DFUE desde el ámbito interno que desde el ámbito europeo (tutelar los derechos desde el estándar europeo puede dar lugar a un resultado diferente a si se tutelan según el estándar nacional, aunque éste esté abierto al sistema europeo).

51 Apartado 48 de la Sentencia. 


\section{III.2 Acotaciones sustantivas (II): Algunas respuestas sobre las cuestiones y límites del control de convencionalidad.}

Las «recientes acotaciones» sustantivas del Tribunal de Justicia (sobre la tutela judicial de los Derechos Fundamentales en el ámbito nacional de aplicación del Derecho de la Unión Europea) de las que hablamos en el título de este trabajo, no están referidas únicamente a cómo y cuándo puede el Juez nacional conjugar los estándares nacionales de protección de los Derechos Fundamentales con los de la UE. Existen, también, ciertas resoluciones que vienen a aportar alguna luz o algún nuevo paso sobre la cuestión relativa a la posibilidad y límites de un control de convencionalidad (CEDH) por parte del Juez nacional que actúa como Juez comunitario frente a la actuación del poder público nacional que entra en el ámbito de aplicación del Derecho de la Unión. ¿Qué postura debe adoptar el Juez nacional que actúa como Juez comunitario ante una norma interna incompatible con las disposiciones del $\mathrm{CEDH}$ que gozan de eficacia directa? ¿Es posible pensar en el CEDH como parámetro o canon iusfundamental «directo» de la «comunitariedad» (o europeidad) de una actuación nacional que aplica Derecho de la Unión? Ahora que ha entrado en vigor el nuevo artículo 6 del TUE reformado en Lisboa, ¿Son suficiente fundamento para ello el nuevo apartado tercero de dicho artículo, que confirma que «los DF que garantiza el CEDH» - y los que son fruto de las tradiciones constitucionales comunes - seguirán formando parte del Derecho de la Unión como principios generales (pese a que el primer apartado del mismo reconoce a la Carta de los DFUE el mismo valor jurídico que los Tratados), y/o los artículos $52.3^{52}$ y $53^{53}$ de la Carta (ahora, como decimos, con la eficacia jurídica vinculante del Derecho originario)? ¿Y qué puede pensarse sobre ese control de convencionalidad en manos del Juez nacional que actúa como Juez comunitario de concretarse el mandato de adhesión a la Unión europea establecido en el artículo $6.2 \mathrm{TUE}^{54}$ ? Veamos hasta dónde llegan las respuestas en las sentencias a los asuntos Kamberaj y (una vez más) Akerberg.

La Sentencia al Asunto Kamberaj5s trae causa de una petición prejudicial planteada por el Tribunal de Bolzano (Italia), en la que se pide al Tribunal de Justicia que se pronuncie sobre la compatibilidad, con el Derecho de la Unión, de un mecanismo de reparto de los fondos destinados a las ayudas a la vivienda creado por la Provincia de Bolzano, el cual viene a ofrecer a los nacionales de países terceros residentes de larga duración un tratamiento menos favorable que el concedido a los ciudadanos de la Unión ${ }^{56}$.

52 «En la medida en que la presente Carta contenga derechos que correspondan a derechos garantizados por el Convenio Europeo para la Protección de los Derechos Humanos y de las Libertades Fundamentales, su sentido y alcance serán iguales a los que les confiere dicho Convenio. Esta disposición no obstará a que el Derecho de la Unión conceda una protección más extensa.»

53 Cuyo contenido ya hemos apuntado supra al final del epígrafe 2.2.

54 «La Unión se adherirá al Convenio Europeo para la Protección de los Derechos Humanos y de las Libertades Fundamentales. Esta adhesión no modificará las competencias de la Unión que se definen en los Tratados.»

55 De 24 de abril de 2012, en el asunto C-571/10.

56 El Sr. Kamberaj, nacional albanés que reside en la Provincia autónoma di Bolzano desde el año 1994, y que es titular de un permiso de residencia de duración indeterminada, fue beneficiario de una «ayuda a la vivienda» de la citada Provincia durante 1998 y 2008, una ayuda que se repartía entre, por una parte, los ciudadanos de la Unión, fuesen o no italianos, y, por otra, los nacionales de países terceros que fueran residentes de larga duración. A partir de 2009, no obstante, este reparto de los fondos concedidos a dichas categorías 
En concreto aquél Tribunal plantea, entre otras, una cuestión prejudicial sobre si, en caso de conflicto entre una norma interna y el CEDH, la referencia al CEDH que hace el anteriormente señalado artículo 6.3 del TUE «obliga al juez nacional a aplicar directamente el artículo $14 \mathrm{CEDH}$ y el artículo 1 del [Protocolo n. ${ }^{\circ} 12$ ], y a no aplicar la fuente interna incompatible, sin deber plantear previamente una cuestión de constitucionalidad ante el Tribunal Constitucional nacional» ${ }^{57}$.

La cuestión se presta a generar respuestas encontradas. Es de destacar, en este sentido, la posición mantenida en el asunto por el Abogado General Yves Bot ${ }^{58}$, quien parece rechazar la oportunidad de esta cuestión al verla como un mero problema de incompatibilidad entre el Derecho nacional y las disposiciones de efecto directo del $\mathrm{CEDH}^{59}$. Y sobre esta base, recuerda que «ha de destacarse que cuando se acude al Tribunal de Justicia al amparo del artículo 267 TFUE, éste es competente para pronunciarse sobre la interpretación de los Tratados y sobre la validez y la interpretación de los actos adoptados por las instituciones de la Unión. La competencia del Tribunal de Justicia se limita únicamente al examen de las disposiciones del Derecho de la Unión $\left[^{60}\right]$. Por lo tanto, carece de competencia para pronunciarse con carácter prejudicial sobre las consecuencias que debe sacar el juez nacional de la posible incompatibilidad entre una norma de Derecho interno y las disposiciones de la $\mathrm{CEDH} .{ }^{61}$

Sin embargo, parece que el Tribunal de Bolzano, interpretaba la cuestión enfocándola desde la base de que, según el nuevo artículo 6.3 TUE, los derechos y libertades reconocidos por el CEDH «forman parte» del Derecho de la Unión (y no «sólo» en el sentido en el que lo hacía el artículo 6.2 del mismo Tratado con anterioridad a la reforma de Lisboa, cuando señalaba que «La Unión respetará los derechos fundamentales tal y como se garantizan en el Convenio»). Y que, en consecuencia, se produciría una suerte de incorporación por referencia del CEDH en el Derecho de la Unión, de manera que dicho Convenio, se

fue calculado de una manera distinta para los ciudadanos de la Unión y para los nacionales de países terceros, siendo denegada la ayuda al Sr. Kamberaj 2009 por parte del Instituto de la Vivienda de la Provincia por haberse agotado el presupuesto destinado a los nacionales de países terceros. Ante ello, el Sr. Kamberaj interpone un recurso ante el Tribunale di Bolzano solicitando que se declarara que dicha decisión constituye una discriminación contraria a la Directiva relativa a los nacionales de países terceros que son residentes de larga duración (2003/109/CE del Consejo, de 25 de noviembre de 2003, relativa al estatuto de los nacionales de terceros países residentes de larga duración). Para un análisis del caso: S. PEERS, «The Court of Justice lays the foundations for the Long-Term Residents Directive: Kamberaj, Commission v. Netherland, Mangat Singh», CMLR, 50 (2), 2013, pp. 529 y ss., espec. 531 y ss.

57 Véase, in extenso, el trabajo de Bianco, G. y Martinico, G., «The poisoned Chalice: An Italian view on the Kamberaj case», Papeles de Derecho Europeo e Integración Regional, WP IDEIR n. ${ }^{\circ} 18$ (2013).

58 Conclusiones presentadas el 13 de diciembre de 2011.

59 Apartado 38 de las Conclusiones. Cabe destacar que el Sr. Yves Bot recuerda, asimismo, que según el señala el propio Tribunal de Bolzano en su resolución de petición prejudicial, de 24 noviembre de 2010, la Corte Costituzionale italiana tiene declarado que dicha incompatibilidad no permite dejar de aplicar la disposición nacional, sino que exige al juez el planteamiento de una cuestión de constitucionalidad en caso de que no le fuera posible hacer respetar el CEDH en aplicación del principio de interpretación conforme. Véanse también, sobre el tema, la Sentencia n. ${ }^{\circ} 349$ del 2007 o la Sentencia n. ${ }^{\circ} 80$ de 2011

$60 \mathrm{Y}$ el Abogado General recuerda aquí, al respecto, las siguientes resoluciones del TJ: de 18 de octubre de 1990, Dzodzi (C-297/88 y C-197/89, apartado 31), y de 1 de junio de 2006, Innoventif (C-453/04, apartado 29), así como el Auto de 1 de marzo de 2011, Chartry (C-457/09, apartado 21, y jurisprudencia citada).

61 Ibid, apartado 39. 
beneficiaría, como parte de este Derecho, de los mismos principios comunitarios de primacía y efecto directo, pudiendo inaplicarse la norma nacional que lo contradiga ${ }^{62}$.

La respuesta a esta segunda prejudicial del caso Kamberaj es clara. Para el TJ, el nuevo artículo $6.3 \mathrm{TUE}^{63}$ «no regula la relación entre el CEDH y los ordenamientos jurídicos de los Estados miembros, ni establece las conclusiones que debe sacar un juez nacional en caso de conflicto entre los derechos que garantiza dicho Convenio y una norma de Derecho nacional». ${ }^{64} \mathrm{Y}$ en consecuencia, señala, procede responder a la cuestión que «la referencia que hace el artículo 6 TUE, apartado 3, al CEDH no obliga al juez nacional, en caso de conflicto entre una norma de Derecho nacional y el CEDH, a aplicar directamente las disposiciones de dicho Convenio y a no aplicar la norma de Derecho nacional incompatible con el mismo» ${ }^{65}$.

Casi un año más tarde, y en la aquí ya reiterada Sentencia Akerberg, el TJ volverá a recordar aquella idea (recordando el parágrafo 62 de la Sentencia Kamberaj), pero ahora desarrollando un poco más la idea previa. En efecto, el Tribunal destacará que, por lo que se refiere a las consecuencias que debe deducir un juez nacional en caso de conflicto entre el Derecho nacional y el CEDH, «debe recordarse que, si bien los derechos fundamentales reconocidos por el CEDH forman parte del Derecho de la Unión como principios generales - como confirma el artículo 6 TUE, apartado 3-, y el artículo 52, apartado 3, de la Carta exige dar a los derechos contenidos en ella que correspondan a derechos garantizados por el CEDH el mismo sentido y alcance que les confiere dicho Convenio, éste no constituye, dado que la Unión no se ha adherido a él, un instrumento jurídico integrado formalmente en el ordenamiento jurídico de la Unión.» ${ }^{66} \mathrm{El}$ interés de lo señalado reside, entre otras cosas, en que apunta, aunque sea de forma sencilla, a que la adhesión a la Unión Europea (recogida como mandato en el art. 6.2 TUE) podría llevar (o no) a una conclusión distinta ${ }^{67}$.

\section{III.3 La posibilidad de combinar la cuestión prejudicial (art. 267 TFUE) y las reglas procesales nacionales}

Conviene comenzar recordando la reiterada jurisprudencia del TJ relativa a que «desde el momento en que una normativa nacional entra en el ámbito de aplicación del

62 Del análisis de la posición del Tribunal de Bolzano hecha por BIANCO, G. y MARTINICO, G., «The poisoned Chalice...», op. cit., p. 9. (Una posición que, por cierto, ya fue rechazada por la Corte Constitucional en la ya citada Sentencia n. ${ }^{\circ} 80 / 2011$, apartado 5.4).

63 Del que vuelve a señalar que «refleja la jurisprudencia reiterada del Tribunal de Justicia según la cual los derechos fundamentales forman parte de los principios generales del Derecho cuyo respeto garantiza el Tribunal de Justicia» (recordando, en particular, la sentencia de 29 de septiembre de 2011, Elf Aquitainel Comisión, C-521/09 P, apar. 112).

64 Apartado 62 de la Sentencia.

$65 \mathrm{Ibid}$, apartado 63.

66 Apartado 44 de la ya citada Sentencia Akerberg (énfasis añadido). Véase también STJ Schindler Holding $L t d$., de 18 de julio de 2013, C-501/11P, ap. 32.

67 En este sentido, Bruno de Witte tiene señalado que el Convenio « (...) will become directly binding on the EU after the Union's accesión» [ «The Use of the ECHR and Convention case law by the ECJ», in P. Popelier, C. Van de Heyning and P. Van Nuffel (eds.), Human rights protection in the European legal order: The interaction between the European and the national courts, Intersentia, Oxford, 2011, pp. 17-33; al respecto: G. Bianco y G. Martinico, «The poisoned Chalice...», op. cit., p. 9]. 
Derecho comunitario, el Tribunal de Justicia, cuando conoce de un asunto planteado con carácter prejudicial, debe proporcionar todos los elementos de interpretación necesarios para la apreciación, por el órgano jurisdiccional nacional, de la conformidad de dicha normativa con los derechos fundamentales cuya observancia garantiza el Tribunal de Justicia, tal como están expresados, en particular, en el Convenio Europeo para la Protección de los Derechos Humanos y de las Libertades Fundamentales» ${ }^{68}$. La cuestión prejudicial, sea de interpretación o de validez, cumple así, una labor determinante en la tutela judicial, por parte del Juez nacional que actúa como Juez comunitario, de los DFUE (sean los reconocidos a título de principios generales o sean los de la Carta de DFUE) en el ámbito interno de aplicación del Derecho de la Unión. El TJ no actúa como Juez que tutela los DFUE en el caso, pues no es el Juez común del mismo. No es esa su competencia. Sin embargo, ayuda en esa labor, que le corresponde, como ya se ha visto, al Juez nacional, a través de la petición prejudicial. La tutela judicial de los DFUE se ve así directamente entreverada y afectada por la propia dinámica de funcionamiento de la cuestión prejudicial y por la autonomía que ésta pueda desplegar respecto al Derecho procesal nacional y al ordenamiento interno en su conjunto.

En efecto, es conocido que, en no pocas ocasiones, van surgiendo una serie de cuestiones acerca de si es posible combinar o conjugar y hasta qué límites, la facultad, y en su caso la obligación, de plantear la cuestión prejudicial con las/algunas normas y reglas procesales internas, cuestiones que, por lo ya señalado, inciden también, siquiera indirectamente, en la tutela judicial nacional de los DFUE. Pues bien, el hecho es que en estos últimos años el TJ ha dictado una serie de interesantes sentencias que han ido acotando y señalando soluciones a algunas de esas diferentes cuestiones ${ }^{69}$. Sentencias y acotaciones a las que aquí, como no puede ser de otra forma, haremos sólo referencia puntual, haciendo dos grupos concéntricos a efectos expositivos.

(a) Por una parte, es posible destacar un grupo general, formado por las sentencias del TJ que vienen a fortalecer, haciéndola «cuasi intocable» ${ }^{70}$ — frente al ordenamiento interno- - la facultad misma de activar la cuestión prejudicial por parte de los órganos jurisdiccionales nacionales que no resuelven en última instancia. Entre la reciente «panoplia jurisprudencial», que tiene su antecedente inicial en la famosa Sentencia Rheinmüblen-Düsseldorf $I^{71}$ (en la que el Tribunal declaró que «una norma de Derecho nacio-

68 Sentencia TJ al asunto Steffensen, de 10 de abril de 2003, C-276/01, apartado 70 (en la que se hace referencia a jurisprudencia previa al respecto: sentencias de 29 de mayo de 1997, Kremzow, C-299/95, apartado 15, y Roquette Frères, de 22 de octubre de 2002, C-94/00, apartado 25). Y conviene asimismo, tener presente que, en cambio, el Tribunal de Justicia no es competente en relación con una normativa que no entra en el ámbito del Derecho comunitario y cuando el objeto del litigio no presenta ningún punto de conexión con Derecho comunitario (ATJ Noël, de 27 de noviembre de 2009, C-333/09, apartado 11 y jurisprudencia allí citada; igualmente las Conclusiones del Abogado General Yves Bot presentadas el 5 de abril de 2011 en el asunto I. Scattolon, apartado 112).

69 Cfr. al respecto, entre otros: Alonso, R., Sistema jurídico de la Unión Europea, op. cit., pp. 195 y ss.; Sarmiento, D., «Cuestión prejudicial y control previo de constitucionalidad. Comentario a la sentencia Melki del Tribunal de Justicia de la UE», REDE, 37, 2011, pp. 100 y ss.

70 Ibid., Alonso, R., p. 96.

71 Sentencia que inaugura una jurisprudencia que reitera, de una u otra forma, que el artículo 267 TFUE otorga a los órganos jurisdiccionales nacionales una amplísima «facultad» para someter la cuestión al Tribunal de Justicia si consideran que un asunto pendiente ante ellos plantea cuestiones que exigen la inter- 
nal, que vincule a los órganos jurisdiccionales que no resuelven en última instancia a las valoraciones jurídicas efectuadas por el órgano jurisdiccional superior, no puede privar a aquéllos de la facultad de someter al Tribunal de Justicia cuestiones de interpretación del Derecho comunitario al que se refieran tales valoraciones jurídicas» ${ }^{72}$ ), destacan de forma llamativa las Sentencias Cartesio, Elchinov o, muy recientemente, Križan.

La Sentencia Cartesio $^{73}$ vino a matizar de forma evidente la jurisprudencia Rheinmüblen-Düsseldorf II (que, además de lo arriba señalado en Rheinmüblen I, admitía también la posibilidad de recurrir internamente las decisiones de plantear la cuestión prejudicial ${ }^{74}$ al afirmar que «la competencia autónoma de acudir ante el Tribunal de Justicia que el artículo $234 \mathrm{CE}$ confiere al primer juez se pondría en tela de juicio si, al reformar la resolución en la que se acuerde la remisión prejudicial, revocarla y ordenar al órgano jurisdiccional que dictó esa resolución proseguir el procedimiento suspendido, el órgano jurisdiccional de apelación pudiera impedir al órgano jurisdiccional remitente ejercer la facultad que le confiere el Tratado CE de plantear la cuestión prejudicial al Tribunal de Justicia» ${ }^{75}$.

La Sentencia Elchinov ${ }^{76}$, por su parte, recordará, en primer lugar, que las normas procesales nacionales no pueden poner en entredicho la facultad que tienen los órganos jurisdiccionales nacionales de plantear al Tribunal de Justicia una petición de decisión prejudicial cuando albergan dudas acerca de la interpretación del Derecho de la Uniónn77,

pretación o la apreciación de la validez de disposiciones del Derecho de la Unión necesarias para la resolución del litigio del que conocen (de 16 de enero de 1974, C-166/73, apartado 3; y como progenie de la misma, entre otras, las SSTJ: de 27 de junio de 1991, Mecanarte, C-348/89, apartado 44; de 10 de julio de 1997, Palmisani, C-261/95, apartado 20; de 16 de diciembre de 2008, Cartesio, C-210/06, apartado 88; de 22 de junio de 2010, Melki y Abdeli, C-188/10 y C-189/10, apartado 41; o Elchinov, de 5 de octubre de 2010, C-173/09, apartado 26), facultad que los órganos jurisdiccionales nacionales pueden ejercerla en cualquier fase del procedimiento que estimen apropiada (STJ Melki y Abdeli, cit., apartados 52 y 57).

72 Apartado 4. Siguiendo las Conclusiones del Abogado General Pedro Cruz Villalón en el caso Elchinov, de 10 de junio de 2010, puede decirse que se trata de «una proclamación que suponía un importante respaldo para la fuerza normativa del Derecho de la Unión, que desde entonces recibía, por este cauce, la posibilidad de imponerse frente a una sentencia de un tribunal superior cuya doctrina vinculaba a la instancia. Aunque la dicción alude únicamente a la facultad de la instancia de plantear la cuestión prejudicial, es obvio que tal planteamiento se realiza a fin de, en su caso, desoír los dictados de la sentencia del tribunal superior» (apartado 20). De manera que, «Rheinmüblen I introducía así una suerte de control descentralizado de comunitariedad, no frente a normas, sino frente a resoluciones judiciales [... ]» (apartado 21).

73 De 16 de diciembre de 2008, C-210/06.

74 De 12 de febrero de 1974, C-146/73; confirmada también, de alguna manera, en Simmenthal (STJ de 9 de marzo de 1978, C-106/77).

75 Apartado 95 de la citada STJ Cartesio. Y es que, en efecto, de conformidad con el artículo 234 CE, la apreciación de la pertinencia y la necesidad de la cuestión prejudicial es responsabilidad única del órgano jurisdiccional que acuerda la remisión prejudicial [ello, sin perjuicio, como recuerda el TJ (apartados 96 y 67), de la comprobación limitada que realiza al respecto el propio Tribunal de Justicia]. Y en consecuencia, «incumbe a ese órgano jurisdiccional extraer las consecuencias de una sentencia dictada en un recurso de apelación contra la resolución por la que se acuerda plantear la cuestión prejudicial y, en particular, llegar a la conclusión de que debe ya mantener su petición de decisión prejudicial, ya modificarla, ya renunciar a ella» (apartado 96). Sobre el asunto Cartesio y sus implicaciones, en profundidad: R. Alonso García, «Cuestión prejudicial comunitaria y autonomía procesal nacional: a propósito del asunto Cartesio, STJUE de 16 de diciembre de 2008 (C-210/06)», REDE, 30, 2009, pp. 197 y ss.

76 De 5 de octubre de 2010, C-173/09.

77 Apartado 25. Véase también la recaída en el asunto Interedil, de 20 de octubre de 2011, C-396/09, apartado 35; STJ Bericap Záródástechnikai GC, de 15 de noviembre de 2012, C-180/11, ap. 54. 
y que el órgano jurisdiccional nacional que no resuelve en última instancia debe tener la libertad de someterle las cuestiones que le preocupan, si considera que la valoración jurídica efectuada por el órgano de rango superior pudiera llevarle a dictar una sentencia contraria al Derecho de la Unión ${ }^{78}$. E incide en que ese juez nacional, que haya ejercido la facultad que le otorga el artículo 267 TFUE (párrafo segundo), «está vinculado, a la hora de resolver el litigio principal, por la interpretación de las disposiciones de que se trate realizada por el Tribunal de Justicia y debe, en su caso, dejar de lado las valoraciones del órgano jurisdiccional superior si, habida cuenta de la antedicha interpretación, estima que las referidas valoraciones no son compatibles con el Derecho de la Unión» ${ }^{79}$. El Tribunal terminará reiterando, en la línea de la jurisprudencia Simmenthal, la obligación del órgano jurisdiccional nacional que actúa como Juez comunitario de garantizar la plena eficacia de estas disposiciones dejando inaplicada en caso de necesidad, por su propia iniciativa, cualquier disposición nacional contraria, también si se trata de normas procesales nacionales, sin solicitar o esperar la derogación previa de dicha disposición nacional por el legislador o mediante cualquier otro procedimiento constitucional ${ }^{80}$.

Continuando por esta senda, la reciente Sentencia al asunto Križan y otros ${ }^{81}$, una vez de reiterar que el Derecho procesal no puede poner en entredicho la facultad que tienen los órganos jurisdiccionales nacionales de plantear al Tribunal de Justicia una petición de decisión prejudicial cuando, como es el caso de autos, albergan dudas acerca de la interpretación del Derecho de la Unión ${ }^{82}$, destacará que ese Juez conserva esa facultad incluso cuando una norma nacional le obliga a seguir la valoración jurídica formulada por el Tribunal Constitucional (en este caso, el eslovaco), debiendo dejar de lado las valoraciones de éste si resultan contrarias al Derecho de la Unión. En concreto, como señaló el TJ, «el artículo 267 TFUE debe interpretarse en el sentido de que un órgano jurisdiccional nacional, como el tribunal remitente, está obligado a plantear de oficio ante el Tribunal de Justicia una petición de decisión prejudicial incluso cuando se pronuncia tras la devolución de los autos a raíz de la casación de su primera resolución por parte del Tribunal Constitucional del Estado miembro de que se trata y cuando una norma nacional le obliga a resolver el litigio siguiendo la apreciación jurídica formulada de este último tribunal» ${ }^{83}$.

El hecho es que las reglas de origen jurisprudencial que aquí se vienen señalando tienen una trascendencia fundamental para que el Juez nacional que actúa como Juez europeo, ese Juez que, como señalábamos con anterioridad, tiene un «doble alma iusfundamental», actúe con libertad si, a la hora de tutelar los Derechos Fundamentales

78 Apartado 27 (recordando, al respecto lo señalado en los apartados 4 y 5 de la aquí arriba comentada STJ Rheinmühlen-Düsseldorf I; apartado 94 de la también apuntada sentencia Cartesio; apartado 32 de la STJ de 9 de marzo de 2010, ERG y otros, C-378/08; o apartado 42 de la también señalada Sentencia Melki y Abdeli).

79 Apartado 30 de la Sentencia.

80 Apartado 31 de la Sentencia. Recientemente: STJ Consiglio Nazionale dei Geologi, de 18 de julio de 2013, C-136/12, ap. 33.

81 De 15 de enero de 2013, C-416/10.

82 Apartado 67 de la Sentencia.

83 Apartado 73 de la Sentencia. Con antelación, sobre la obligación de inaplicar normas nacionales contrarias a Derecho comunitario, «independientemente de la decisión del tribunal constitucional nacional de posponer la pérdida de vigencia de esas disposiciones, declaradas inconstitucionales»: STJ Filipiak, de 19 de noviembre de 2009, C-314/08, apart. 85. 
en el ámbito de aplicación interna del Derecho de la Unión, considera que debe realizar una petición prejudicial: (i) incluso habiendo ya una decisión sobre la materia realizada por el Tribunal Constitucional, o (ii) porque considera que la valoración jurídica efectuada por éste o por un órgano de la jurisdicción ordinaria de rango superior podría llevarle a dictar una sentencia contraria al Derecho de la Unión.

(b) Por otra parte, de forma concéntrica y casi nuclearizada al grupo jurisprudencial anterior, surge otro grupo de sentencias emitidas por el TJ en los últimos años que, además de confirmar la «filosofía» Rheinmülen-Düsseldorf (I) sobre la mencionada autonomía de la facultad judicial de activar la prejudicial respecto al Derecho procesal nacional (y al ordenamiento interno en su conjunto), la extenderá con fuerza también sobre el contexto de las relaciones e imbricaciones de la petición prejudicial con los controles de constitucionalidad de las normas con rango de ley.

Ahí está, por ejemplo, la STJ al asunto Kücükdeveci ${ }^{84}$, que trae causa de una petición prejudicial de un tribunal de instancia alemán preguntando sobre la eventual obligación del juez nacional, que conoce de un litigio entre particulares, de plantear al Tribunal de Justicia dicha cuestión antes de poder dejar sin aplicación una disposición nacional que estime contraria al Derecho de la Unión [teniendo en cuenta que, según se desprende de la resolución de remisión, con arreglo al Derecho interno, el órgano jurisdiccional remitente no puede abstenerse de aplicar una disposición vigente de la legislación nacional sin que dicha disposición haya sido previamente declarada inconstitucional por el Bundesverfassungsgericht (Tribunal Constitucional Federal Alemán]. Lo que estaba en juego, obviamente, es si la jurisprudencia Simmenthal lleva consigo una obligación positiva de plantear la cuestión prejudicial antes de que se pueda inaplicar una norma nacional con rango de ley. Frente al temor de que una obligación así condujera a desincentivar la aplicación de esa jurisprudencia fundamental ${ }^{85}$, el Tribunal de Justicia vino a subrayar que (la necesidad de garantizar la plena eficacia del principio de no discriminación por razón de la edad, tal como se concreta en la Directiva 2000/78, implica que) «el juez nacional, ante una disposición nacional comprendida en el ámbito de aplicación del Derecho de la Unión que estime incompatible con dicho principio y cuya interpretación conforme a éste resulte imposible, debe abstenerse de aplicar dicha disposición, sin estar obligado a plantear previamente una petición de decisión prejudicial al Tribunal de Justicia ni estar impedido para hacerlo» ${ }^{86}$.

Pero, eso sí, el TJ añadió, además, que «la facultad así reconocida al juez nacional por el artículo 267 TFUE, párrafo segundo, de solicitar una interpretación prejudicial del Tribunal de Justicia antes de dejar sin aplicación la disposición nacional contraria al Derecho de la Unión no puede, sin embargo, transformarse en una obligación por el hecho de que el Derecho nacional no permita a dicho juez abstenerse de aplicar una disposición nacional que estime contraria a la Constitución sin que dicha disposición haya sido previamente declarada inconstitucional por el Tribunal Constitucional» ${ }^{87}$. El carácter facultativo de la remisión es independiente de los procedimientos que el Derecho inter-

84 De 19 de enero de 2010, C-555/07.

85 Cfr. Sarmiento, D., «Cuestión prejudicial y control previo de constitucionalidad...», op. cit., p. 102.

86 Apartado 53 de la Sentencia (énfasis añadido).

87 Apartado 54 de la Sentencia (énfasis añadido). 
no imponga al juez nacional para dejar sin aplicación una disposición nacional que éste estime contraria a la Constitución ${ }^{88}$. Se trata, por lo demás, de una regla que debe también ser tenida en cuenta en nuestro ordenamiento constitucional, especialmente cuando una resolución como la STC 194/2006, de 19 de junio (posteriormente rectificada ${ }^{89}$ ) transformaba, precisamente, aquella facultad de plantear la prejudicial en obligación. ${ }^{90}$

No obstante, la decisión más llamativa al respecto sea, quizás, la Sentencia al asunto $M e l k i^{91}$, la cual versa directamente sobre las posibilidades y límites que se le plantean al Juez nacional que actúa como Juez comunitario cuando se enfrenta a una ley nacional que puede ser contraria a pari a la Constitución nacional y al Derecho de la UE. Como es sabido, el artículo 61.1 de la Constitución Francesa de 1958 (en su versión modificada en la reforma constitucional de 23 de julio de 2008), y sobre el mismo, el legislador francés (Ley Orgánica n..$^{\circ}$ 2009/1523, de 10 de diciembre de 2009), han venido a configurar un procedimiento incidental de control de constitucionalidad de las leyes nacionales, la llamada Question prioritaire de constitutionnalité (QPC). En función de esta regulación, en lo sucesivo, el Juez ordinario se ve en la obligación de examinar si la ley nacional aplicable al caso es conforme con los derechos y libertades que garantiza la Constitución nacional, elevando en caso de duda la correspondiente cuestión de inconstitucionalidad al Consejo Constitucional Francés (a través de la intervención de la Corte de Casación o del Consejo de Estado, según el juez de fondo sea judicial o administrativo $)^{92}$. Pero todo ello con la particularidad de que, en virtud de aquella regulación, dicha cuestión debe plantearse con carácter preferente o "prioritario» a cualquier otro procedimiento, incluido el planteamiento de la cuestión prejudicial. El asunto Melki consiste en una cuestión prejudicial planteada por la Corte de Casación francesa preguntando, precisamente, sobre si el Derecho de la Unión se opone a ese carácter preferente de la QPC ante el Consejo Constitucional sobre el reenvío prejudicial ante el TJ cuando una ley nacional infrinja tanto derechos fundamentales reconocidos por la Constitución nacional como el Derecho de la Unión Europea y/o los DF reconocidos por éste.

La respuesta del TJ fue una Sentencia en la que el TJ concluye, en primer lugar, que «el artículo 267 TFUE se opone a una normativa de un Estado miembro que establece un procedimiento incidental de control de constitucionalidad de las leyes nacionales, en

88 Apartado 55.

89 Véase infra apartado 4.2.

90 Distinta es la situación que se da, como recuerda el profesor Alonso García, R., (Sistema jurídico..., op. cit., p. 198), cuando lo que acontece es una «imposición de la obligación de plantear la cuestión prejudicial no como requisito previo para inaplicar leyes, sino para activar el mecanismo interno de control de constitucionalidad de las mismas: mientras que aquella imposición es incompatible con el Derecho de la Unión, en la medida en que desvirtúa el poder-deber de inaplicación derivado del propio Derecho de la Unión, ésta incide en el modus operandi de un mecanismo interno de control de la ley por inconstitucional (no por contraria al Derecho europeo), que al propio Derecho interno corresponde definir ( $c f r$. al respecto el Auto del TC Federal alemán de 4 de octubre de 2011, 1 BvL 3/08)».

91 Sentencia de 22 de junio de 2010, recaída en los asuntos Aziz Melki (C-188/10) y Sélim Abdeli (C-189/10)

92 Sobre el tema, entre otros: Requejo Rodríguez, P., Cuestión prioritaria y defensor de los derechos ¿pervive la excepción francesa?, Civitas, Madrid, 2011; León Alonso, M., «La cuestión prioritaria de constitucionalidad: un nuevo desafío para la justicia constitucional francesa», en Revista General de Derecho Público Comparado, 10, 2012; MAUGÜE, Ch. y STAHL, J-H., La question prioritaire de constitutionalité, Dalloz, París, 2012. 
la medida en que el carácter prioritario de ese procedimiento tenga como efecto impedir, tanto antes de la remisión de una cuestión de constitucionalidad al órgano jurisdiccional nacional competente para ejercer el control de constitucionalidad de las leyes como, en su caso, después de la resolución del citado órgano sobre dicha cuestión, que todos los demás órganos jurisdiccionales nacionales ejerzan su facultad o cumplan su obligación de plantear cuestiones prejudiciales al Tribunal de Justicia». Y tras ello, establece, asimismo, una compatibilidad de la QPC con el mencionado art. 267 TFUE (que regula la prejudicial) «condicionada» a que los demás órganos jurisdiccionales nacionales sigan estando facultados: (a) para plantear al Tribunal de Justicia toda cuestión prejudicial que consideren necesaria, en cualquier momento del procedimiento que estimen apropiado, e incluso una vez finalizado el procedimiento incidental de control de constitucionalidad; (b) para adoptar toda medida necesaria para asegurar la tutela judicial provisional de los derechos conferidos por el ordenamiento jurídico de la Unión, y (c) para dejar inaplicada, una vez finalizado ese procedimiento incidental, la disposición legislativa nacional controvertida si la consideran contraria al Derecho de la Unión ${ }^{93}$. Unido a ello, añade, además, un supuesto en el que la cuestión prejudicial aparece como prioritaria respecto a la QPC. Y se produce cuando el juez de fondo se enfrenta a una ley nacional que implementa normas imperativas de una Directiva (y ello porque sólo el TJ tiene competencia para declarar inválido un acto de la Unión ${ }^{94}$, ya que lo contrario, la aplicación prioritaria de la QPC, llevaría al Consejo Constitucional a realizar un control indirecto de la Directiva $\left.{ }^{95}\right)^{96}$.

\section{III.4 La cuestión prejudicial y el CEDH}

Conviene comenzar apuntando, antes de nada, el hecho de que también existe la posibilidad de recurrir el no planteamiento de la cuestión prejudicial ante el TEDH, una vez agotada la vía jurisdiccional interna (art. $35 \mathrm{CEDH}$ ), por vulneración del derecho a un proceso equitativo reconocido en el art. 6.1 del Convenio. Hay que señalar, sin embargo, que dicho Tribunal viene exigiendo, para admitir tal vulneración, que la decisión de no plantear aquella sea una decisión arbitraria ${ }^{97}$.

93 Apartado 57 de la Sentencia Melki.

94 Véase, por todas, la Sentencia de 22 de octubre de 1987, as. Foto-Frost (314/85), apartados 15-20.

95 Apartado 56 de la Sentencia Melki.

96 Sobre el caso Melki, ex plurimis, Sarmiento, D., «Cuestión prejudicial y control previo de constitucionalidad...», op. cit., pp. 97 y ss. Alonso, R., Sistema jurídico de la Unión Europea, op. cit., pp. 198-199; Ferreres, V., «El problema del «doble vicio» en que pueden incurrir las leyes nacionales: infracción de la Constitución e infracción del Derecho de la Unión Europea. A propósito del caso Melki», Actualidad Jurídica Uría Menéndez, 28, 2011, pp. 57 y ss. [autor, este último, que profundiza en las razones por las que, en atención al propio art. $163 \mathrm{CE}$ y en ausencia de una regla sobre la prioridad de la cuestión de inconstitucionalidad como la francesa, en nuestro ordenamiento el Juez nacional que actúa como Juez comunitario deberá dar prioridad a la petición prejudicial ante el problema del «doble vicio» — de una ley simultáneamente contraria a la Constitución y al Derecho de la UE- (pp. 60-61)].

97 Véanse, entre las más recientes: Jobn v. Alemania, de13 de febrero de 2007; Herma v Alemania. Decisión sobre admisibilidad de 8 de dic. de 2009; o Ullens de Schooten y Rezabak v. Bélgica, de 20 de sept. de 2011; apartados 54 y s. Por otro lado, levantando la presunción de equivalencia (general establecida en el asunto Bosphorus, relativa a que el sistema de protección del Derecho de la UE es equivalente al del convenio) en el 
Pero la idea que interesa destacar en este contexto es la preocupación que el TJ ha manifestado recientemente sobre la problemática situación que podría generar, tras la adhesión de la Unión al CEDH, el no planteamiento de la cuestión prejudicial en relación a la tutela de los derechos del CEDH en aquellos supuestos en los que el TEDH resolviera sobre la conformidad de un acto de la Unión con aquél Convenio sin que previamente el propio TJ haya podido pronunciarse de forma definitiva sobre la cuestión ${ }^{98}$. Se estaría obviando el papel de Luxemburgo en el depuramiento del ordenamiento jurídico de la Unión. Y ello porque salvo que el procedimiento, establecido con la adhesión, se dirija de forma directa e inicial contra la Unión, el previo agotamiento de las vías jurisdiccionales contra el Estado miembro no garantizaría que los Tribunales nacionales del mismo hayan dado al TJ la oportunidad de conocer de forma efectiva sobre la cuestión de validez de un acto de la Unión antes de que el TEDH se pronuncie sobre su conformidad con el Convenio. El problema surgiría pues, en los recursos interpuestos ante Estraburgo contra Estados miembros de la Unión en un contexto de ejecución (de forma particular en los casos de ejecución reglada) del Derecho de la Unión en el que el Juez nacional que está en el origen del litigio omite el planteamiento de la cuestión prejudicial ex art. 267 TFUE. A falta de otro remedio al respecto, tampoco hay que escatimar la importancia que pueda llegar a desarrollar como posible solución, siquiera parcial, que el propio TEDH siga consolidando su doctrina, arriba apuntada, de vincular la negativa arbitraria a activar el 267 TFUE con una vulneración del derecho a un proceso equitativo reconocido en el art. 6.1 del Convenio 99.

\section{BREVES APUNTES SOBRE LAS RECIENTES ACOTACIONES DEL TRIBUNAL CONSTITUCIONAL}

\section{IV.1 Acotaciones en la dimensión sustantiva: la STC 145/2012}

Como hemos podido observar en este trabajo, las Sentencias Melloni y Akerberg ponen en cuestión la concepción del Tribunal Constitucional acerca del parámetro de control iusfundamental que debe utilizar el Juez nacional al controlar la actividad interna de aplicación del Derecho de la Unión. Se lean como se lean, estas Sentencias, especialmente la recaída en el asunto Melloni, están empujando e incluso obligando, al

caso en cuestión, dada la debilidad de la cuestión prejudicial en orden a controlar el respeto de los Derechos Fundamentales: Michaud vs. France, de 6 de diciembre de 2012.

98 Véase al respecto el Documento de reflexión del Tribunal de Justicia de la Unión Europea de 5 de mayo de 2010, sobre ciertos aspectos de la adhesión de la Unión Europea al Convenio Europeo para la protección de los derechos bumanos $y$ de las libertades fundamentales (apartados 9 y 12).

99 In extenso sobre el tema: Alonso García, R., «Lisboa y el Tribunal de Justicia de la Unión Europea», op. cit., pp. 29 y 30; del mismo: Sistema jurídico..., op. cit., pp. 209 y ss.; véase, igualmente, IrURZUN Montoro, F., «La adhesión de la Unión Europea al Convenio Europeo de Derechos Humanos. Una crónica inacabada», REDE , 45, 2013, pp. 9 y ss., espec. 14 y ss; M. AzPITARTe, «Autonomía del ordenamiento de la Unión y Derechos Fundamentales: ¿presupuestos contradictorios? La adhesión al Convenio Europeo. de Derechos Humanos como respuesta», REDE, n. ${ }^{\circ}$ 48, 2013. 
menos al Juez nacional de aplicación, a terminar de forma efectiva con una inercia conceptual que sigue defendiendo el carácter absoluto de la «soberanía» y/o el «monopolio» iusfundamental nacional sobre la actuación estatal que entra en el radio de acción del Derecho de la Unión ${ }^{100}$.

No es fácil precisar, especialmente, a la luz de la adusta respuesta del Tribunal de Justicia a las cuestiones prejudiciales planteadas en el ATC 86/2011, cuál será la reacción que tendrá el Tribunal Constitucional en la sentencia de amparo consiguiente, si habrá un giro doctrinal, o probablemente una modulación. Parece descartable el choque real con el Tribunal de Justicia (a la luz de lo señalado en la TC 1/2004) y, en cualquier caso, deseable perseverar en los encomiables intentos de diálogo prejudicial) ${ }^{101}$. La posición del Tribunal Constitucional debe, de cualquier manera, ser leída a la luz de los esfuerzos de «normalización constitucional» del Derecho de la UE que está realizando el Tribunal Constitucional ${ }^{102}$.

Se trata de unos esfuerzos que admiten ya que la cuestión de la aplicación judicial del Derecho comunitario puede tener, si no un rango constitucional, sí una cierta relevancia constitucional. Así lo ha hecho, por ejemplo: (1) al considerar, como tendremos ocasión de apuntar más adelante, que las resoluciones judiciales por las que se inaplican Leyes internas sin plantear previamente una cuestión prejudicial ante el Tribunal de Justicia de la Unión Europea (cuando era procedente a la luz de las normas del Derecho de la Unión) pueden tener implicaciones constitucionales (SSTC 58/2004, de 19 de abril; STC 194/2006, de 19 de junio; y la STC 78/2010 de 20 de octubre). (2) Así puede ser igualmente entendido, obviamente, con el propio planteamiento, por primera vez, de las cuestiones prejudiciales que lleva a cabo el Tribunal mediante el descrito ATC 86/2011, Auto del que trae causa la Sentencia Melloni. (3) Y esa es también, la lectura que hay que hacer de la STC 145/2012, de 2 de junio, en la que se otorga un amparo por vulneración del derecho a la tutela judicial efectiva (art. 24.1) 103 $^{10}$ a la legalidad sancionadora (art. 25.1 CE), declarando la nulidad de una sanción administrativa y de dos resoluciones judiciales que generaban aquella vulneración al aplicar legislación nacional que había sido declarada contraria al Derecho comunitario por el Tribunal de Justicia en el marco de un recurso por incumplimiento ${ }^{104}$. El TC es cada vez más sensible a la relevancia y a las implicaciones constitucionales de la aplicación judicial del Derecho de la UE, y en esa línea, puede acabar siéndolo también para con la obligación

100 Cfr. Ugartemendia, J.I. y Ripol Carulla, S., «La Euroorden ante la tutela de los Derechos Fundamentales...», op. cit., passim, espec. apartado V.

$101 \mathrm{Al}$ respecto, en profundidad: Díez-Hochleitner, J., «El derecho a la última...», op. cit., espec. el apartado III.

$102 \mathrm{Al}$ respecto, véase el trabajo de Arroyo JiménEz, L., «Hacia una normalización constitucional del Derecho de la Unión Europea. A propósito de la STC 145/2012, de 2 de julio», REDE, 45, 2013, pp. 139-169.

103 En su manifestación de un derecho a obtener una resolución motivada y fundada en Derecho sobre el fondo de las pretensiones deducidas por las partes, en concreto, sin que se incurra en una selección irrazonable y arbitraria de la norma aplicable al proceso.

104 STJ de 17 de julio de 2008, as. Comisión contra España, C-207/07. Sobre la STC 145/2012, en profundidad: Arroyo Jiménez, L., «Hacia una normalización constitucional del Derecho de la Unión Europea...», op.cit., pp. 139 y ss.; SARMIENTO, D., «Reinforcing the (domestic) constitutional protection of primacy of EU law. Tribunal Constitucional (Spanish constitutional court), Judgment 145/2012 of 2 July 2012, Iberdrola v. Comisión Nacional de la Energía», CMLR, 50 (3), 2013, pp. 875 y ss. 
de ese Juez nacional de tener que respetar los DFUE, al menos en las condiciones marcadas por la regla de las situaciones establecida en Melloni y Akerberg.

En cualquier caso, parece que quien se verá obligado a respetar la resolución $M e-$ lloni (y en general, la «regla de las situaciones» ya señalada), no pudiendo condicionar la entrega del mismo de la forma que sugería el ATC 86/2011, es el Juez nacional de aplicación del DUE. Y ello debido a que lo decidido en la Sentencia Melloni es ahora particularmente vinculante para el Juez nacional. Y no sólo porque ello viene establecido de forma clara por una decisión prejudicial del Tribunal de Justicia, de modo que una resolución contraria podría derivar en incumplimiento del Derecho de la Unión ${ }^{105}$. Sino que, también, porque la ya mencionada STC 145/2012, de 2 de junio, ha reconocido de forma expresa, precisamente, que no tener en cuenta las resoluciones del Tribunal de Justicia que son determinantes para la interpretación y aplicación nacional de Derecho de la Unión (en el caso, la señalada Sentencia de 17 de julio de 2008, recaída en el marco de un recurso por incumplimiento), puede implicar una vulneración del derecho fundamental a la tutela judicial efectiva del art. 24.1 CE, en su manifestación de un derecho a recibir una sentencia motivada y fundada en Derecho (en concreto, por incurrir en una selección irracional y arbitraria de la norma aplicable en el proceso).

\section{IV.2 Acotaciones sobre la tutela de los Derechos Fundamentales en relación a la petición prejudicial}

Existe también una serie de recientes resoluciones del Tribunal Constitucional que vienen a incidir sobre la relación existente entre, por una parte, la facultad y, en su caso, la obligación del Juez nacional de realizar una petición prejudicial, y por otra, la función tuitiva que corresponde al mismo de llevar a cabo una tutela judicial de los Derechos Fundamentales (se entiende, en el «ámbito de aplicación interna del Derecho de la Unión»). Podríamos decir, en este sentido, que el Tribunal Constitucional ha tenido ocasión de abordar durante los recientes años tres distintos tipos de cuestiones relativas a esa relación, las cuáles vamos a pasar a apuntar de forma muy abreviada.

En primer lugar, se encuentra el hecho, muy significativo, de que el propio Tribunal Constitucional, sin ser juez nacional que aplica Derecho de la Unión, haya planteado, sin embargo, su primera petición prejudicial, en virtud del ya analizado ATC 86/2011, de 9 de junio, actuando como «órgano jurisdiccional nacional» (art. 267 TFUE) a efectos de realizar la mencionada remisión ${ }^{106}$. Y ello, aunque lo haya hecho no con la idea de aplicar la norma europea cuya interpretación solicita (y validez cuestiona, en el caso de la segunda de las tres cuestiones planteadas), sino, a la postre, de «controlar» si el Juez nacional que actúa como Juez comunitario realiza una tutela correcta de

$105 \mathrm{Y}$ por lo demás, sobre la posibilidad de una eventual responsabilidad del Estado por manifiesta violación del Derecho de la Unión por parte del Juez nacional (de última instancia), véanse las SSTJ: de 30 de septiembre de 2003, as. Koebler, C-224/01; de 13 de junio de 2006, as. Traghetti del Mediterraneo, C-173/03; y de 24 de noviembre de 2011, as. Comisión c. Italia, C-379/10.

106 Sobre la tradicional negativa previa del Tribunal Constitucional a plantear la cuestión prejudicial vid., por ejemplo: Ugartemendia, J.I. y Ripol Carulla, S., Continuismo y ¿novedad?..., op. cit., pp. 4 y ss., y las referencias bibliográficas allí señaladas. 
los Derechos Fundamentales reconocidos por la Constitución nacional. La prejudicial del TC está dirigida a establecer un diálogo jurisdiccional «constitucional» con el TJ ${ }^{107}$ con el objeto de llegar a un buscar un punto de encuentro donde converjan de forma óptima la lectura nacional y europea de los estándares de protección de los Derechos Fundamentales que debe realizar el Juez nacional encargado de aplicar Derecho de la Unión.

En segundo lugar, existen también sentencias del TC que inciden en el tema del eventual entrecruzamiento entre la facultad u obligación judicial de realizar la petición prejudicial y el planteamiento de la cuestión de inconstitucionalidad (art. 163 CE). Ya hemos tenido ocasión de señalar que la Sentencia Kücükdeveci (2010) dejó bien sentada la regla de que la facultad (del Juez nacional que aplica Derecho de la Unión) de solicitar una interpretación prejudicial del Tribunal de Justicia antes de dejar sin aplicación la disposición nacional contraria a ese Derecho no puede ser transformada en obligación por el Derecho interno por el hecho de que el Derecho nacional no permita inaplicar una norma nacional que estime contraria a la Constitución sin que antes haya sido declarada inconstitucional por el $\mathrm{TC}^{108}$. La regla merece ser observada con especial atención teniendo en cuenta que la STC 194/2006, de 19 de junio, vino, precisamente, a realizar algo parecido a ese tipo de transformación, ya que, como se ha dicho, de la argumentación «se desprende implícitamente que el TC, pese a asumir que no se daban las condiciones para plantear la cuestión prejudicial, siquiera en términos facultativos, estimó que dicho planteamiento era ineludible como condictio sine qua non para inaplicar la ley» ${ }^{109}$. Una actitud que luego se vio reflejada, incluso con más claridad, en la Sentencia del Tribunal Supremo (Sal Tercera), de 17 de julio de 2009, donde se concluye que «el juicio negativo, por tanto, sobre la falta de acomodación de la ley española - RD Ley 5/2004 - a la norma comunitaria —Directiva 2003/87 - precisa, para que dejemos de aplicar una norma con rango de ley, el planteamiento de una cuestión prejudicial». En cualquier caso, el TC tuvo oportunidad de adecuarse a la jurisprudencia Kücükdeveci poco más tarde, en la STC 78/2010, de 20 de octubre, señalando de forma clara y expresa, ya en el primer Fundamento Jurídico, «que el Tribunal ha avocado este recurso de amparo para que sea conocido por el Pleno — arts. 10.1.n) y 13 LOTC_, a fin de fijar nuestra doctrina sobre la cuestión prejudicial del Derecho comunitario, rectificando la que deriva de la STC 194/2006, de 19 de junio».

Finalmente, tenemos también ciertas Sentencias del Tribunal Constitucional, algunas ya citadas, que inciden sobre una tercera dimensión de la relación entre la cuestión prejudicial y la tutela judicial de los Derechos Fundamentales en el ámbito de aplicación nacional del Derecho de la Unión. Se trata de aquellas en las que el TC ha dado a entender que el no planteamiento de la cuestión prejudicial puede generar una vulneración, susceptible de tutela mediante amparo constitucional, de diversas manifestaciones

107 En relación a la labor del TJ como jurisdicción constitucional, entre otros: DíEz-HochleITNER, J., «El derecho a la última palabra...», op. cit., pp. 5 y ss.; SÁIz Arnaiz, A., «El Tribunal de Justicia de las Comunidades Europeas como Tribunal Constitucional», en Morodo Leoncio, R.; De Vega García (Coords.), Estudios de teoría del Estado y derecho constitucional en honor de Pablo Lucas Verdú Vol. 4, 2001, pp. 2425-2462.

108 Véase supra el apartado (III.3.b).

109 Alonso García, R., «Cuestión prejudicial europea...», op. cit., p. 8. 
del Derecho Fundamental a la tutela judicial efectiva según estándares definidos en el art. 24 CE. En concreto, de manifestaciones como el Derecho Fundamental a un proceso con todas las garantías del (art. 24.2 CE) ${ }^{110}$, o a obtener una resolución motivada y fundada en Derecho (art. 24.1 CE) ${ }^{111}$. Supuestos todos ellos, donde la vulneración viene generada por un no planteamiento de la cuestión prejudicial que lleva parejo como efecto la inaplicación de una norma nacional (la norma nacional que se estima contraria a la norma europea sobre cuya dudosa interpretación había que haber planteado una prejudicial $)^{112}$. No obstante, es interesante señalar, asimismo, la STC 27/2013, de 12 de marzo, en la que se produce un supuesto en el que se estudia si la vulneración de la tutela judicial podía haber derivado de una falta de remisión prejudicial al TJUE que tenía como efecto aparejado, no la inaplicación de norma legal interna alguna (como ocurría en el asunto 58/2004 o en la también citada 78/2010), sino, por el contrario, la aplicación de una disposición interna controvertida porque se la considera compatible con la norma europea sobre cuya interpretación se han proyectado las dudas ${ }^{113}$.

\section{IV.3 A modo de conclusión: el Derecho Fundamental a la tutela judicial efectiva (art. $24 \mathrm{CE}$ ) como cláusula de integración iusfundamental.}

Una vez analizadas algunas cuestiones relativas a la tutela judicial de los Derechos Fundamentales en el ámbito de aplicación nacional del Derecho de la Unión, el objetivo de las siguientes líneas consiste, simplemente, en apuntar el «potencial integrador» que desprende el propio Derecho Fundamental a la tutela judicial efectiva, especialmente del reconocido en la Constitución nacional (art. $24 \mathrm{CE}$ ).

Ya hemos visto al examinar el caso Melloni que la tutela judicial efectiva reconocida en la Carta de DFUE (arts. 47 y 48) es un instrumento vital para la garantía, en el ordenamiento interno, de los derechos reconocidos por la Unión. Aquí hay un caso en el que se observa con claridad que la concepción de la Unión sobre la tutela judicial efectiva comienza a pesar de forma ostensible. Pero también hemos podido observar en el propio asunto Melloni que es, precisamente, el celo porque exista una correcta tutela del Derecho Fundamental del art. 24 CE por parte del Juez nacional que aplica Derecho de la Unión Europea lo que ha empujado al Tribunal Constitucional a tratar de trabar

110 Véase la STC 58/2004, de 19 de abril: vulneración de la tutela judicial efectiva en su manifestación de derecho a un proceso con todas las garantías, cuando el Juez ordinario, por su propia autoridad, inaplica una norma de rango legal por contraria al Derecho de la Unión, resultando procedente el planteamiento de la cuestión prejudicial en términos obligatorios — según lo establecido por el 267 TFUE a la luz de la jurisprudencia del TJUE al respecto-

111 Véase, al respecto, la STC 78/2010, de 20 de octubre.

112 Sobre el tema, entre otros: Alonso García, R., «Cuestión prejudicial europea y tutela judicial efectiva...», op. cit., pp. 12 y ss.; y en su Sistema jurídico..., op. cit., pp. 199 y ss. Arroyo Jiménez, L., «Hacia una normalización constitucional del Derecho de la Unión Europea..., op. cit., pp. 139 y ss. Asimismo, IzQUierdo SANS, C., «Cuestión prejudicial y artículo 24 de la Constitución española», RGDE, núm. 23, 2011; Morcillo Moreno, J., «El planteamiento de la cuestión prejudicial comunitaria a la luz de la jurisprudencia europea y constitucional: facultad o deber?», RAP, núm. 185, 2011, pp. 227 y ss.; Huelin MARTíNEZ De Velasco, J., «Las implicaciones constitucionales...», op. cit., pp. 375 y ss.

113 Véanse FFJJ 2 y ss., y especialmente el voto particular a la misma formulado por la Magistrada Doña Adela Asua Batarrita. 
un diálogo constitucional con el Tribunal de Justicia a través del planteamiento de su primera cuestión prejudicial (ATC 86/2011, de 9 de junio). Y de igual manera, acabamos de señalar, asimismo, que el Tribunal Constitucional ha dictado ya varias Sentencias en las que da relevancia constitucional (en atención a la protección del estándar nacional de la tutela judicial efectiva, esto es del Derecho Fundamental del art. 24 CE) a la aplicación judicial (comunitaria o europeamente) incorrecta del Derecho de la Unión, llegando a tutelar en amparo vulneraciones de algunas manifestaciones o concreciones de dicho Derecho Fundamental ${ }^{114}$.

En este sentido, se podría aventurar que el Derecho Fundamental a la tutela judicial efectiva está jugando un papel de integración constitucional nacional de los derechos reconocidos por la Unión similar, mutatis mutandis, al que lleva a cabo el art. 10.2 CE. Es conocido que este artículo se configura como una cláusula de apertura constitucional al Derecho supranacional e internacional de los derechos humanos, incluido el de los DFUE (cosa que, por ejemplo, puede acontecer, ahora ${ }^{115}$, en una situación que hemos definido como «situación Akerberg» o de margen de actuación normativa en la aplicación del Derecho de la Unión). Y en esa medida la cláusula del 10.2 CE cumple con una función de integración iusfundamental (de integración de estándares de protección nacionales y europeos en materia de derechos fundamentales), y dicho con mayor perspectiva, una función de integración constitucional entre el ordenamiento europeo y el nacional.

Pues bien, aunque el 24 CE no es, obviamente, una «cláusula de apertura (constitucional)» al estilo del 10.2 CE, el cual viene a la postre a nacionalizar, en su caso, DFUE a través de una integración de los mismos en los derechos constitucionales, sí es, sin embargo, al igual que aquella, un mecanismo de integración nacional de los derechos reconocidos por ordenamiento europeo (incluidos los DFUE), al menos, en la medida en que se configura como un instrumento de tutela de esos derechos, esto es, como una «cláusula constitucional tuitiva» de los derechos reconocidos por el ordenamiento de la Unión. Si la virtualidad integradora del artículo 10.2 CE se concreta al configurarse como un mecanismo de apertura constitucional a los DFUE, el potencial integrador del artículo 24 CE se articula, de otro modo, al actuar como una instrumento que garantiza, a través de la jurisdicción ordinaria, el respeto del Derecho de la Unión y de los derechos — fundamentales o no_- reconocidos por éste en el orden interno.

Pero, hay que partir de la base de que el Derecho Fundamental a la tutela judicial efectiva que rige en el ámbito de la Unión no es sólo el establecido en el art. 24 CE. Debemos recordar una vez más que, siguiendo el artículo 51.1 de la Carta y la jurisprudencia Wachauf, el estándar de protección del DF a la tutela judicial efectiva que debe regir cuando se aplica Derecho de la Unión en el ámbito nacional (al tutelar o proteger los derechos reconocidos en esas normas) es el estándar europeo, esto es, el reconocido en

114 Derivadas, normalmente, del no planteamiento de la cuestión prejudicial. Pero hay, también, casos en los que la vulneración de un Derecho Fundamental a obtener una resolución motivada y fundada en Derecho (art. 24.1 CE) trae causa de la aplicación judicial de legislación nacional declarada —en el marco de un recurso por incumplimiento contraria a Derecho por el TJ (vid. la ya comentada STC 145/2012, de 2 de julio).

115 Una vez que los DFUE (sea en calidad de principios generales de la Unión, sean los de la Carta ahora - tras la reforma de Lisboa - jurídicamente vinculante) son de respeto comunitariamente obligado (jurisprudencia Wachauf y art. 51.1 Carta) en el ámbito interno. 
los arts. 47 y 48 de la Carta, además del identificable en la concepción de dicho derecho como principio general del Derecho de la Unión (si seguimos los dictados del art. 6.3 TUE). La STJ Melloni es una buena prueba de ello. No obstante, y afinando un poco más a la vista de la arriba descrita «regla de las dos situaciones» establecida en el combinado jurisprudencial Melloni/Akerberg, hay que señalar que, pese a todo, el estándar nacional del Derecho Fundamental a la tutela judicial efectiva (esto es, el establecido en el art. 24 CE, según es identificado por el TC) puede llegar a tener también su amplio espacio en el ámbito nacional cuando se aplica Derecho de la Unión. Así ocurrirá si es que nos encontramos en el prototipo de la situación Akerberg o tesitura en la que el Estado tienen margen de maniobra en la aplicación normativa del Derecho de la Unión (y siempre que, claro está, con ello no se rebaje el nivel establecido por la Carta de DFUE, o se atente contra la primacía, unidad y efectividad del Derecho de la Unión).

Además, y en cualquier caso, se trate de la tutela judicial efectiva en la situación Akerberg o en la situación Melloni, lo realmente interesante a la hora de reconocer el Derecho Fundamental a la tutela judicial cotidiana de cualquier derecho reconocido por el ordenamiento de la Unión, una tutela que, recordemos, debe, en principio, desarrollar el Juez nacional (jurisdicción ordinaria), consiste en que el Tribunal Constitucional puede, como se ha visto, llegar a garantizar en amparo, en atención a meros parámetros constitucionales nacionales de la tutela judicial efectiva, si ese Juez nacional ha protegido adecuadamente esos derechos reconocidos por la Unión (incluidos, en su caso, los DFUE). Así puede ocurrir, por ejemplo, como hemos visto, si ese juez inaplica una ley nacional sin plantear la cuestión prejudicial, cuando esto era comunitariamente preceptivo (STC 58/04), o cuando aplica una ley nacional que ha sido declarada contraria a Derecho de la Unión (STC 145/2012). Ello sin perjuicio de que el Tribunal Constitucional continúe con su habitual inhibición a ser Juez de comunitariedad. Y aunque para ello, pese a todo, tenga que llegar a plantear cuestiones prejudiciales (una vez que ya ha abierto la vía con el ATC 86/2011, de 9 de junio ${ }^{116}$ ). Es aquí donde, con ello, puede observarse que el art. $24 \mathrm{CE}$ ha comenzado a ser la vía desde la que, poco a poco, puede ir desarrollarse un diálogo jurisdiccional (a través de la prejudicial) entre el TC y el TJ con el objeto de integrar la concepción nacional y eurocomunitaria de los Derechos Fundamentales que debe manejar el Juez nacional en el ámbito interno de aplicación del Derecho de la Unión.

TíTLE: The judicial protection of fundamental rights in the sphere of the national application of EU Law. Recent remarks by the Court of Justice and by the Spanish Constitutional Court.

AвSTRACT: This article deals with the judicial protection of fundamental rights when EU Law is applied at national level and the main problems national judges have to deal with when applying EU Law as protectors of rights. More

116 Si bien es verdad que en este caso el planteamiento obedecía a establecer un «diálogo» desde el que conciliar la lectura constitucionalmente correcta de un Derecho fundamental a un proceso con todas las garantías según es tutelado en atención al estándar de protección constitucional nacional con la tutela del mismo Derecho pero a la luz del estándar europeo de protección del mismo ( 47 y 48.2 de la Carta de DFUE), y no sólo a garantizar que el juez nacional aplicador del Derecho tutele el Derecho según éste último estándar europeo. 
precisely, the work is focused on the examination of some recent and decisive judicial decisions, both by the European Court of Justice and by the Spanish Constitutional Court which analyze the problems and address the solutions to those questions besides showing the evolution and current situation in that regard. They are decisions that deal with the merits as for example to which extent it might be possible to use national standards of protection of fundamental rights in situation. connected to EU Law or to its application instead of using the system of protection of EU buman rights. Likewise, they are decisions which handle with more procedural questions as for example to what extent national judges are autonomous to file a preliminary question (it is understood that when it comes time to protect rights acknowledged by the EU) relative to national procedural rules.

RESUMEN: Este artículo es un estudio relativo a la tutela judicial de los Derechos Fundamentales cuando se aplica Derecho de la Unión en el ámbito interno, y a cuáles son los principales problemas con los que se topa el Juez nacional que aplica el Derecho de la Unión al llevar a cabo dicha función protectora. El trabajo, dicho de forma más concreta, se centra en el examen de una serie de recientes y decisivas resoluciones jurisdiccionales, dictadas tanto por parte del Tribunal de Justicia de la Unión Europea como por parte del Tribunal Constitucional Español, que analizan problemas y señalan soluciones relativas a esas cuestiones, además de mostrar cuál es la evolución y el estado de la situación al respecto. Se trata de resoluciones que abordan cuestiones de fondo, como, por ejemplo: ¿ hasta qué punto es posible utilizar estándares nacionales de protección de los Derechos Fundamentales en situaciones conectadas con el Derecho de la Unión o con su aplicación, en lugar de utilizar el sistema de protección de los Derechos Fundamentales de la Unión Europea? Y asimismo, resoluciones que atienden a cuestiones de dimensión más procesal como la de dirimir hasta quépunto tiene autonomía el Juez nacional a la hora de plantear una petición prejudicial (se entiende a la hora de tutelar derechos reconocidos por normas de la Unión) en relación a las normas procesales nacionales.

KEYWORDS: Fundamental Rights and European Union; Effective Judicial protection; Preliminary question

Palabras Clave: Derechos Fundamentales y Unión Europea. Tutela judicial efectiva. Cuestión prejudicial.

FECHA DE RECEPCIÓN: 01.07.2013. FECHA DE ACEPTACIÓN: 30.07.2013. 